\title{
Activation of Glutamatergic Fibers in the Anterior NAc Shell Modulates Reward Activity in the aNAcSh, the Lateral Hypothalamus, and Medial Prefrontal Cortex and Transiently Stops Feeding
}

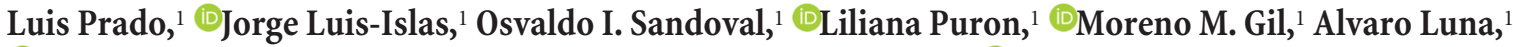 \\ (D) Mario A. Arias-García, ${ }^{2}$ Elvira Galarraga, ${ }^{2}$ Sidney A. Simon, ${ }^{3}$ and ${ }^{D}$ Ranier Gutierrez ${ }^{1}$ \\ ${ }^{1}$ Laboratory of Neurobiology of Appetite, Department of Pharmacology, CINVESTAV, 07360 Mexico City, Mexico, ${ }^{2}$ Instituto de Fisiología Celular, UNAM, \\ 04510, Mexico, and ${ }^{3}$ Department of Neurobiology, Duke University Medical Center, Durham, North Carolina 27710
}

\begin{abstract}
Although the release of mesoaccumbal dopamine is certainly involved in rewarding responses, recent studies point to the importance of the interaction between it and glutamate. One important component of this network is the anterior nucleus accumbens shell (aNAcSh), which sends GABAergic projections into the lateral hypothalamus $(\mathrm{LH})$ and receives extensive glutamatergic inputs from, among others, the medial prefrontal cortex ( $\mathrm{mPFC}$ ). The effects of glutamatergic activation of aNAcSh on the ingestion of rewarding stimuli as well as its effect in the LH and MPFC are not well understood. Therefore, we studied behaving mice that express a light-gated channel (ChR2) in glutamatergic fibers in their aNAcSh while recording from neurons in the aNAcSh, or mPFC or LH. In Thy1-ChR2, but not wild-type, mice activation of aNAcSh fibers transiently stopped the mice licking for sucrose or an empty sipper. Stimulation of aNAcSh fibers both activated and inhibited single-unit responses aNAcSh, $\mathrm{mPFC}$, and $\mathrm{LH}$, in a manner that maintains firing rate homeostasis. One population of licking-inhibited pMSNs in the aNAcSh was also activated by optical stimulation, suggesting their relevance in the cessation of feeding. A rewarding aspect of stimulation of glutamatergic inputs was found when the Thy1-ChR2 mice learned to nose-poke to self-stimulate these inputs, indicating that bulky stimulation of these fibers are rewarding in the sense of wanting. Stimulation of excitatory afferents evoked both monosynaptic and polysynaptic responses distributed in the three recorded areas. In summary, we found that activation of glutamatergic aNAcSh fibers is both rewarding and transiently inhibits feeding.
\end{abstract}

Key words: feeding; glutamatergic afferents; licking; optogenetics; reward; Thy1-ChR2

Significance Statement

We have established that the activation of glutamatergic fibers in the anterior nucleus accumbens shell (aNAcSh) transiently stops feeding and yet, because mice self-stimulate, is rewarding in the sense of wanting. Moreover, we have characterized single-unit responses of distributed components of a hedonic network (comprising the aNAcSh, medial prefrontal cortex, and lateral hypothalamus) recruited by activation of glutamatergic aNAcSh afferents that are involved in encoding a positive valence signal important for the wanting of a reward and that transiently stops ongoing consummatory actions, such as licking.

\section{Introduction}

The anterior nucleus accumbens (aNAcSh) is an area involved in feeding and is one component of a network that plays a critical

Received May 17, 2016; revised 0ct. 9, 2016; accepted 0ct. 14, 2016.

Author contributions: L. Prado, S.A.S., and R.G. designed research; L. Prado, J.L.-I., 0.I.S., L. Puron, M.M.G., M.A.A.-G., E.G., and R.G. performed research; M.M.G., and E.G. contributed unpublished reagents/analytic tools; L. Prado, J.L.-I., 0.I.S., L. Puron, A.L., E.G., S.A.S., and R.G. analyzed data; S.A.S. and R.G. wrote the paper.

This work was supported in part by CONACyT Grants CB179484, Salud 2010-02-151001, ICYTDF-PICSA12-126, Productos Medix 001276, Fronteras de la Ciencia 63, and Problemas Nacionales 464 to R.G. We thank the OIL Stanford workshop for invaluable help; and Fabiola Hernandez Olvera, Richard Gaxiola, and Benjamin Chavez Alvarez for invaluable animal care. role in reward (Kelley and Berridge, 2002; Robinson and Berridge, 2008). One GABAergic projection of the aNAcSh is to the lateral hypothalamus $(\mathrm{LH})$, a region that, when inhibited, results in suppression of feeding, whereas, when activated, increases food intake (Jennings et al., 2015). Input to the aNAcSh arises from glutamatergic fibers, including those from the mPFC, ven-

The authors declare no competing financial interests.

Correspondence should be addressed to Dr. Ranier Gutierrez, Laboratory of Neurobiology of Appetite, Department of Pharmacology, CINVESTAV, 07360 Mexico City, Mexico. E-mail: ranier@cinvestav.mx.

D0I:10.1523/JNEUROSCI.1605-16.2016

Copyright $\odot 2016$ the authors $\quad$ 0270-6474/16/3612511-19\$15.00/0 
tral hippocampus, and BLA (Arenkiel et al., 2007). It has been found that activation of these excitatory glutamatergic fibers is rewarding because mice learned to nose-poke to self-stimulate them, suggesting that, regardless of its source, the release of glutamate into the NAc is reinforcing (Britt et al., 2012). Here we explore how the circuit encompassing the aNAcSh, LH, and mPFC modulates reward and consumption.

Pharmacological studies have shown that inhibition of aNAcSh neurons by GABA $A_{A}$ agonists increases food intake (Stratford and Kelley, 1997). In contrast, electrical stimulation of aNAcSh fibers transiently stops feeding (licking) for sucrose, indicating that this brain region plays a dual role in feeding since inhibition increases it, whereas bulk electrical stimulation decreases it (Krause et al., 2010). With regard to the role of the aNAcSh in feeding, it was found that inhibitory D1-expressing medium spiny neurons $\left(\mathrm{MSND}^{+}\right)$were the major source of inhibition of GABAergic LH neurons (O'Connor et al., 2015) and that the activation of these neurons promotes both the appetitive (wanting) aspect of reward and the consumption of foods (Jennings et al., 2015). Thus, inhibition of MSND1 ${ }^{+}$ neurons prolongs feeding, whereas their activation stops feeding (O'Connor et al., 2015).

Reward-related responses are also found in the aNAcSh (Lobo et al., 2010), and the mesoaccumbal dopaminergic system is a critical component for the incentive motivation (i.e., wanting) of palatable food rewards (Robinson and Berridge, 2008). Although dopamine (DA) has often been attributed to mediate the rewarding properties of the aNAcSh, its interaction with glutamate has also been indicated in mediating reward (Stuber et al., 2011; Britt et al., 2012).

To explore the role of glutamate in feeding and reward, we used Thy1-ChR2 mice that express high levels of ChR2-EYFP primarily in glutamatergic pyramidal projection neurons in the mPFC as well as other areas, including the thalamus and BLA (Arenkiel et al., 2007), that send glutamatergic input to both MSNs and interneurons in the aNAcSh (Sciamanna et al., 2015). We recorded single units from the aNAcSh, $\mathrm{mPFC}$, and $\mathrm{LH}$ while Thy1-ChR2 mice self-photostimulated excitatory aNAcSh afferents while them freely licked for sucrose. We found that optogenetic stimulation of glutamatergic afferents both activates and inhibits local aNAcSh neurons, in a manner that maintains a firing rate homeostasis. We also found that stimulation of glutamatergic aNAcSh fibers transiently stopped mice licking for sucrose and modulated a population of neurons that decreased activity with consumption and covaried with optical stimulation, suggesting their relevance in the cessation of feeding. We also found that Thy1-ChR2 mice self-stimulated the aNAcSh glutamatergic inputs either by licking an empty sipper or by nosepoking, implying that the stimulation produced the wanting aspect of reward (Berridge and Kringelbach, 2015) that is independent of sucrose's caloric and hedonic content. In summary, we have shown how activation of glutamatergic fibers in the aNAcSh modulates both reward and feeding.

\section{Materials and Methods \\ Subjects}

B6.Cg-Tg (Thy1-COP4/EYFP) 18Gfng/J (Thy1-ChR2-EYFP line 18) mice (hereafter referred as Thy1-ChR2 mice) were purchased from The Jackson Laboratory (RRID:IMSR_JAX:007612). These mice expressed the light-activated ion channel, Channelrhodopsin-2 (ChR2), fused to Yellow Fluorescent Protein (EYFP) under the control of the mouse thymus cell antigen 1 (Thy1) promoter (Arenkiel et al., 2007). For all experiments, we used adult male and female mice (3-7 months; see Fig. 1)

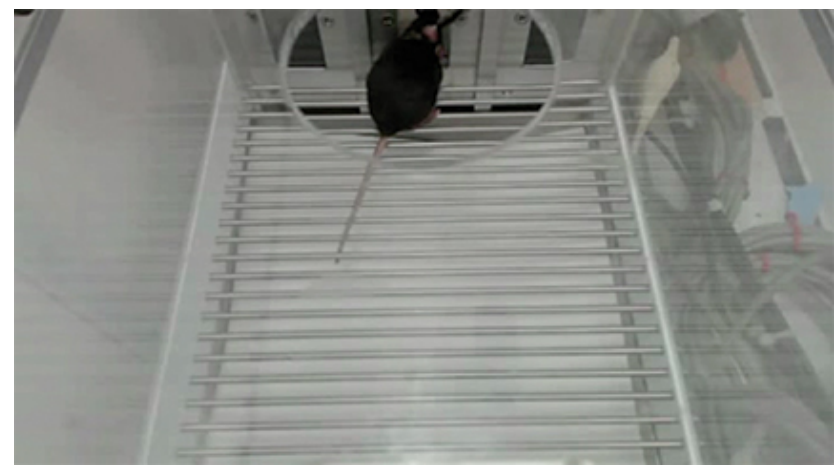

Movie 1. Closed-loop licking task.

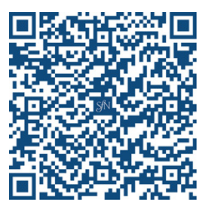

because thy 1 gene expression stabilizes during adulthood (Porrero et al., 2010). All procedures were performed with the approval of the Centro de Investigación y de Estudios Avanzados del Instituto Politécnico Nacional Institutional Animal Care and Use Committee.

\section{Behavioral methods}

Closed-loop freely licking task. In this task, each trial consisted of three epochs: (1) Before (laser, control), (2) Laser, and (3) Time out (laser off) (see Fig. 2A).

Before epoch. Each mouse had to lick for sucrose $(10 \% \mathrm{w} / \mathrm{v})$ delivered from a gravity fed sipper for at least, three times. Laser epoch: On the fourth lick, a laser (Laserglow Technologies) was activated for $1 \mathrm{~s}$ at different frequencies (no-stimulation (Control) or $30 \mathrm{~ms}$ pulse width at $4,7,14$, or $20 \mathrm{~Hz}$ ) in a pseudorandom order, so that the animal could not predict which stimulation frequency it would receive. Time out: For the $1 \mathrm{~s}$ following Laser epoch, the laser, could not be reactivated. To "close the loop," the subsequent four licks after the Time out epoch was the start of the next "Before" epoch (see Fig. 2A). This task is considered a closedloop because, by licking, the animals could control the number of trials per session (in 30 min; see Figs. 2-4; see Movie 1). In one type of experiment (see Fig. 3), we quantified the number of laser pulses (30 ms width) needed to stop licking (only the $20 \mathrm{~Hz}$ stimulation frequency was used).

To evaluate whether Thy1-ChR2 mice could intracranially selfphotostimulate excitatory afferents, we used a new group of naive mice. These mice were given $7 \mathrm{~d}$ to learn to lick an empty sipper to optogenetically activate aNAcSh glutamatergic fibers (see Fig. 4, left panels). At the end of this session, the same animals were provided with the same sipper, but it was now filled with $10 \%$ (w/v) sucrose (see Fig. 4, right panels).

To further demonstrate that $20 \mathrm{~Hz}$ optogenetic activation of glutamatergic inputs in Thy1-ChR2 mice were rewarding, regardless of their ability to stop licking, a new set of mice $(n=3)$ were trained to selfstimulate in a behavioral box (Med Associates) equipped with 2 nosepoke compartments (Britt et al., 2012). The positions of the Active and Inactive ports were counterbalanced between animals. A nose-poke given to the Active port activated a clicker (Med Associates) and triggered a $20 \mathrm{~Hz}$ train of optical stimulation ( $30 \mathrm{~ms}$ width; $15 \mathrm{~mW}$ ) during $1 \mathrm{~s}$. This was followed by a $4 \mathrm{~s}$ Time out epoch. The next nose-poke after this epoch triggered another bout of stimulation. Responses to the Inactive port only triggered the clicker (Med Associates) but had no other programmed consequence (see Movie 2; Fig. 5). The animals learned to self-stimulate in $\sim 3-4 \mathrm{~d}$ (data not shown); and once they gave at least four continuous sessions with constant self-stimulation (see Fig. $5 A$ ), the positions of the Active and Inactive ports were reversed (see Fig. $5 B$ ).

Open-loop freely licking task. This protocol consisted of 5 min blocks of optical stimulation separated by 5 min unstimulated blocks (see Fig. 6). In the stimulated blocks, mice received a continuous $1 \mathrm{~s}$ "On" and $2 \mathrm{~s}$ "Off" stimulation protocol $(20 \mathrm{~Hz} ; 30 \mathrm{~ms}$ pulse width at $15 \mathrm{~mW})$. The total duration of the session was $30 \mathrm{~min}$. 


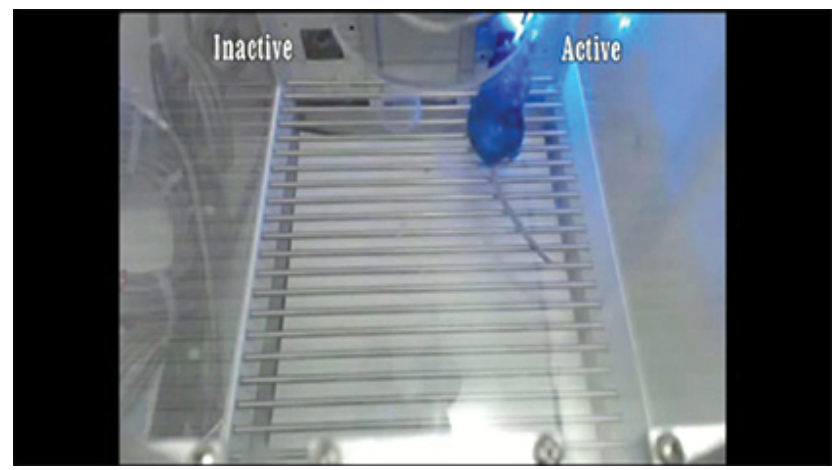

Movie 2. Nose-poke self stimulation task.

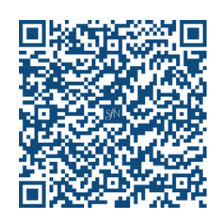

To uncover the neuronal correlates of this open-loop stimulation task, we recorded from the aNAcSh from a new set of transgenic mice $(n=5)$ while mice performed a task identical to the task mentioned above, except that an additional block of $5 \mathrm{~min}$ ( -5 to $0 \mathrm{~min}$ ) was added to record a baseline activity where mice had no access to sucrose. At time $0 \mathrm{~s}$, the experimenter manually introduced a bottle filled with $10 \%$ sucrose (see Fig. $6 C-E)$ and extracellular single-unit recordings continued for another $30 \mathrm{~min}$.

\section{Fiber implantation}

All fiber optics (Thorlabs) and homemade optrodes were implanted unilaterally in the anterior aNAcSh at anteroposterior $=1.2, \mathrm{~L}=1$, and dorsoventral $=-5$. For all experiments, the implanted hemisphere was counterbalanced. No significant differences were found between hemispheres (data not shown). For some animals, in addition of the optic fiber implanted in the aNAcSh, we also implanted a $16,4 \times 4$, channel array either in the LH (anteroposterior $=-1.34$, $\mathrm{L}=1.2$, dorsoventral $=-5.1$ ) (Jennings et al., 2015), or in the mPFC, on the border between prelimbic and infralimbic cortices (anteroposterior $=1.94, \mathrm{~L}=0.3$, dorsoventral $=2.8$ ). This area was chosen because it sends glutamatergic fibers to the aNAcSh (Britt et al., 2012).

\section{Optrode recordings}

A homemade optrode comprised of an array of 16 tungsten wires (35 $\mu \mathrm{m}$ ) surrounding (in a circular configuration) a single multimode optic fiber $200 \mu \mathrm{m}$ in diameter $(\mathrm{NA}=0.39)$ was unilaterally implanted in the aNAcSh. The laser power at the tip of the fiber optic was measured with a power meter (Thorlabs). A fixed power of $15 \mathrm{~mW}$ was used across the sessions to produce a predicted irradiance of $109 \mathrm{~mW} / \mathrm{mm}^{2}$. This light intensity was chosen because, in pilot experiments, we found that a low light intensity $(1.5 \mathrm{~mW})$ did not prevent sucrose feeding (data not shown), whereas stimulating at $15 \mathrm{~mW}$ markedly stopped feeding (see Fig. 7). Thus, photostimulation at $15 \mathrm{~mW}$ of glutamatergic fibers in the aNAcSh activated aNAcSh neurons and transiently stopped animals from feeding (licking).

\section{Data analysis and statistics \\ Multitaper coherence}

Multitaper coherence was computed by segmenting laser pulses and spike trains (in each trial) and chunking them into two univariate binned point processes (Jarvis and Mitra, 2001). The coherence $(C)$ between the laser activation and the spike trains was computed using the following formula: $C(f)=I_{x y} / \sqrt{ }\left(I_{x x} I_{y y}\right)$, where $I_{x x}$ is the spectrum of laser frequencies, $I_{y y}$ is the spectrum of neuronal activity, $I_{x y}$ is the cross-spectrum of the laser and spike spectra, and $f$ is the frequency where coherence was computed. Four frequency windows were used: ( $3-5 \mathrm{~Hz}$ to detect $4 \mathrm{~Hz}$ phased-locked activity and 6-8 for $7 \mathrm{~Hz}, 13-15$ for $14 \mathrm{~Hz}$, and $19-21$ for
$20 \mathrm{~Hz}$ ). The coherence $(C)$ is normalized to range between 0 and 1 . The CI of the coherence $C(f)$ and significance threshold (at $\alpha=0.05 \%$ ) were computed with a jackknife method and finite size corrections using the procedures developed by Jarvis and Mitra (2001). A neuron was classified as laser-coherent only if its lower CI (95\%) crossed the significance threshold (Gutierrez et al., 2010).

\section{Putative classification of neurons in the aNAcSh}

As previously detailed (Tellez et al., 2012), aNAcSh neurons were classified into putative cell types (MSNs, fast spiking interneurons [FSIs], ChAT interneurons, and neurons that did not fit into one of these categories ( $\mathrm{U}$ for unidentified) according to four features: firing rate, coefficient of variation 2 (CV2), valley-to-amplitude ratio (VAR) (Yarom and Cohen, 2011), and valley-to peak width (V-P width). Briefly, the firing rate was calculated as the number of spikes divided by the duration of a 5 min baseline activity before the session began. The CV2 was calculated for each adjacent pair of interspike intervals (ISIs), and the average CV2_ISI was used in the assignment of neuronal type. The two-ISI coefficient of variation was computed as CV2_ISI_|2(ISI2_ISI1)/(ISI2_ISI1)| (Holt et al., 1996). The VAR was calculated as the absolute value of the first valley in the waveform divided by the difference between its minimum value and the following maximum. For computation of the V-P width, the time between the minimum value and the following maximum was calculated. For each neuron recorded, these four features were computed and classified into four clusters by using a fuzzy cluster algorithm and visualized by using principal component analysis (PCA) as seed, followed by the fuzzy Sammon's mapping plot as described in the MATLAB Fuzzy Clustering and Data Analysis Toolbox (The MathWorks).

\section{Neuronal population PCA}

To determine, at the population level, the most common activation pattern, we computed the single value decomposition of the $n \times m$ matrix X ( $n=$ neurons recorded), which contained the binned ( $5 \mathrm{~ms}$ bin size) $Z$-score normalized peristimulus time histogram (PSTH) responses of all neurons recorded $\sim-0.5$ to $2 \mathrm{~s}$ from laser stimulation (trials types were concatenated across $m$ columns). Each neuron was sorted using the loadings of the first PCA (see Fig. 7C) (Horst and Laubach, 2013). This analysis was computed in MATLAB using the following line code:

$$
[U, s, v]=\operatorname{svd}\left(\mathrm{X}^{\prime}, 0\right) ; \mathrm{Z}=\mathrm{X} \times \mathrm{U} ;[\mathrm{n}, \mathrm{nn}]=\operatorname{sort}(\mathrm{Z}(:, 1)) ;
$$

$\operatorname{imagesc}(\mathrm{X}(\mathrm{nn}(:, 1),:))$ colormap jet; set(gca, 'clim',

$$
[-4,4]) \text {; colorbar. }
$$

Unless otherwise mentioned, the data are presented as mean \pm SE. For both behavioral studies and to identify neuronal inhibition or activation induced by the photostimulation, we used a two-way ANOVA followed by Fisher's post hoc analysis.

\section{A fit to a robust linear regression model for the delay to resume licking for sucrose}

To determine the contribution of the firing rate during the Laser and Time out epochs for each neuron in the prediction of the delay to resume licking. We model in a trial-by trial- basis the delay to resume licking (in seconds) as a linear function of the average firing rate in the $1 \mathrm{~s}$ Laser and in the Time out epochs. Following the Wilkinson notation, our model was the following:

$$
\text { Lick Delay } \sim 1+\text { Laser }_{F R}+\text { Time out }_{F R}
$$

Where 1 is the intercept. This analysis was computed in MATLAB using the following line code:

$l m=$ fitlm $(X$, Lick Delay, 'linear', 'Robustopts', 'on'); Tbl

$$
\text { = anova }(\mathrm{lm})
$$

Where $\mathrm{X}$ is an $n \times m$ matrix containing the firing rate in each $n$ trial (all trials included Ctrl, $4-20 \mathrm{~Hz})$ for the two estimated coefficients $(m=2$ 

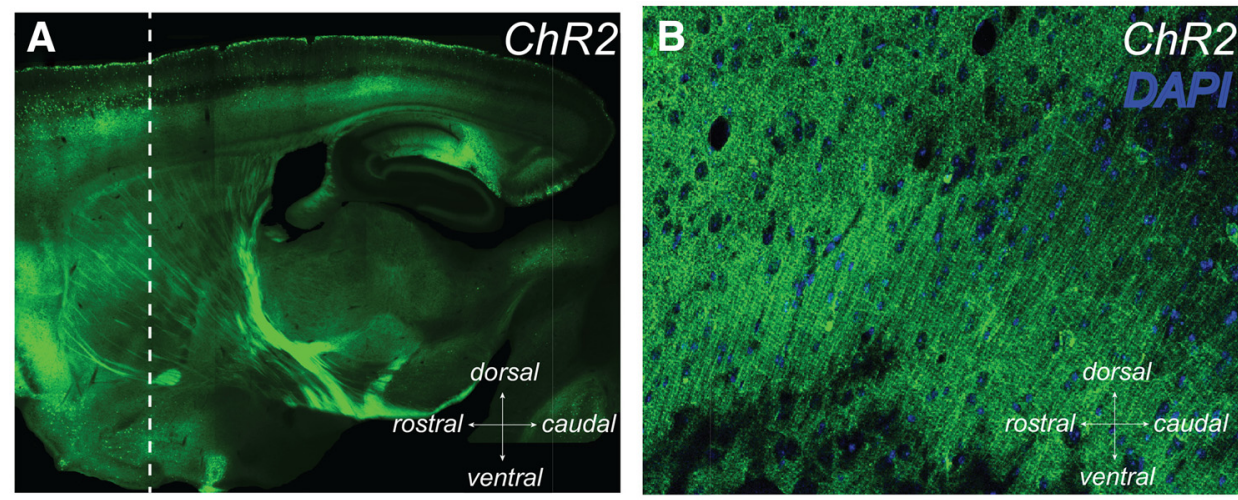

C
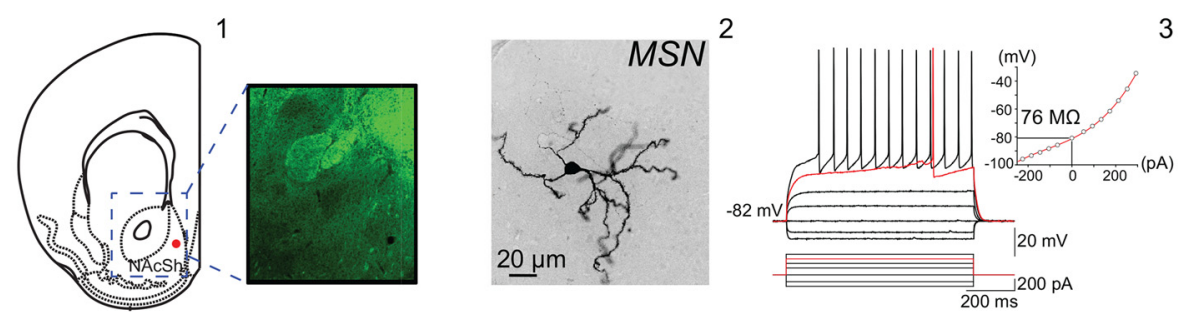

D

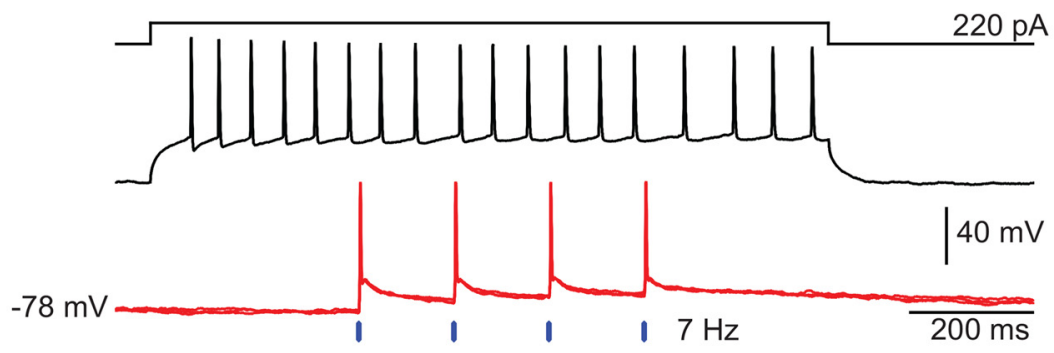

E
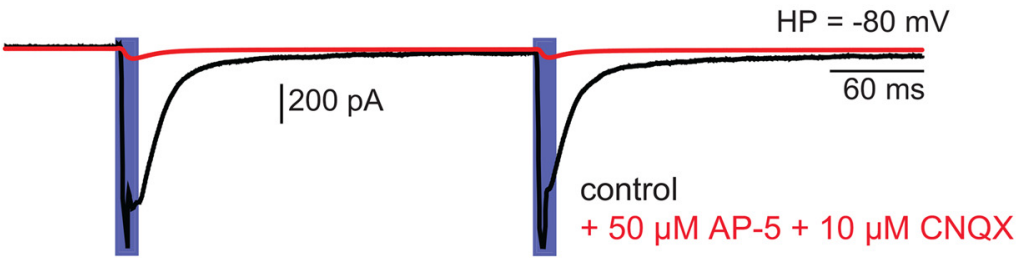

$\mathbf{F}$

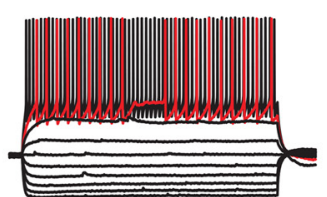

G

$120 \mathrm{mV} 200 \mathrm{~ms} \quad \mathrm{I} 200 \mathrm{pA}$
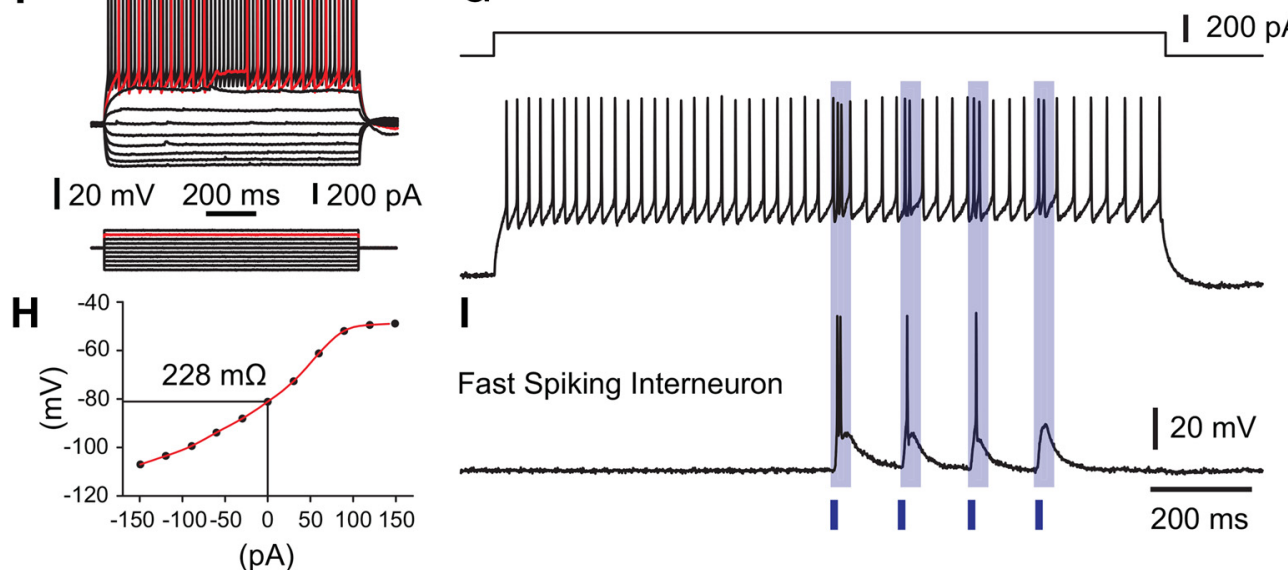

Figure 1. Optogenetic activation of glutamatergic axon fibers activates local aNACSh medium spiny neurons and fast spiking interneurons. $A$, A parasagittal brain section of a transgenic mouse expressing the light-gated ion channel, ChR2(H134R)-EYFP. The section shows ChR2 -expressing neurons located at cortical layer V with dense staining of their corticospinal efferent fibers and corticostriatal fibers (Porrero et al., 2010). Dashed line indicates the anteroposterior level of coronal slices used for in vitro experiments. B. Close-up of a sagittal view of aNAcSh cell bodies stained with DAPI showing that the expression of ChR2-EYFP is generally excluded from cell bodies but is abundant in afferent fibers. C1, Schematic drawing indicating, with a red dot, where intracellular recordings were made. Inset, Coronal brain section of a Thy1-ChR2 mouse. The heavy fiber density. C2, Photomicrograph of an MSN with a high density of dendritic spines. This neuron, located in the aNAcSh, was filled with biocytin after electrophysiological recordings. C3, Voltage responses to hyperpolarized and depolarized current injections into (Figure legend continues.) 
columns): one for the firing rate in the Laser epoch and the second one for the Time out. The LickDelay is a row vector containing the delay (in seconds) to resume licking. The significance of each coefficient was computed using an ANOVA with an $\alpha<0.05$, and the number of neurons with at least 1 significant coefficient was reported in Results.

Latency onset analysis. The onset of light-induced evoked responses was computed by using a cumsum statistic (Gutierrez et al., 2006) to obtain the first bin $(1 \mathrm{~ms} \leq$ resolution $)$ after the first laser pulse that significantly increased firing rate above baseline activity ( -100 to $0 \mathrm{~ms}$ ) that preceded optical stimulation. Monosynaptic responses from the aNAcSh to the other areas were assigned to have a latency of $\leq 10 \mathrm{~ms}$ (Buonomano, 2003).

\section{Preparation of brain slices}

Brain slices were obtained from adult Thy1-ChR2 mice. Mice were deeply anesthetized with $150 \mathrm{mg} / \mathrm{kg}$ ketamine and $30 \mathrm{mg} / \mathrm{kg}$ xylazine intraperitoneally and transcardially perfused with ice-cold, modified Ringer's solution containing the following (in $\mathrm{mm}$ ): 248 sucrose, $2.5 \mathrm{KCl}$, $7 \mathrm{MgCl}_{2}, 23 \mathrm{NaHCO}_{3}, 1.2 \mathrm{NaH}_{2} \mathrm{PO}_{4}, 7$ glucose, 1 ascorbate, 3 pyruvate adjusted to $\mathrm{pH} 7.3$ by bubbling with $95 / 5 \% \mathrm{O}_{2} / \mathrm{CO}_{2}$. The brain was rapidly removed into a beaker containing ice-cold oxygenated Ringer's and trimmed to a block containing the striatum. Coronal sections (250$300 \mu \mathrm{m}$ ) were obtained with a vibratome in the same medium (Pelco 101 Series 1000) and immediately transferred to normal Ringer's solution containing the following (in mM): $124 \mathrm{NaCl}, 2.5 \mathrm{KCl}, 1.2 \mathrm{NaH}_{2} \mathrm{PO}_{4}, 26$ $\mathrm{NaHCO}_{3}, 1.3 \mathrm{MgCl}_{2}, 2 \mathrm{CaCl}_{2}, 10$ glucose, 1 ascorbate, 3 pyruvate, and 0.4 myoinositol adjusted to $\mathrm{pH} 7.3$ by bubbling with $95 / 5 \mathrm{O}_{2} / \mathrm{CO}_{2}$ for $1 \mathrm{~h}$ before recording. The slices were maintained at room temperature until use whereupon they were transferred to the recording chamber and submerged in continuously flowing oxygenated buffer $(2-4 \mathrm{ml} / \mathrm{min})$.

\section{Whole-cell recordings}

Recordings were made at room temperature $\left(\sim 24^{\circ} \mathrm{C}\right)$ from neurons located in the aNAcSh and were visualized in infrared differential interference contrast videomicroscopy with an $40 \times$ water-immersion objective. Micropipettes for whole-cell recording were constructed from $1.5 \mathrm{~mm}$ OD borosilicate pipettes (WPI) on a Sutter P-87 horizontal puller. The standard internal solution for whole-cell patch-clamp recording was (in mM) as follows: $120 \mathrm{KMeSO}_{4}, 2 \mathrm{MgCl}_{2}, 10$ HEPES, $2 \mathrm{Na}_{2} \mathrm{ATP}, 0.2 \mathrm{GTP}$, 10 EGTA, $1 \mathrm{CaCl}_{2}$, and $0.1 \%-0.3 \%$ biocytin, $\mathrm{pH} 7.3-7.4$. These pipettes typically exhibited a DC impedance of $4-6 \mathrm{M} \Omega$ measured in the recording chamber.

Voltage and current-clamp recordings were made with an AxoClamp 2B amplifier (Molecular Devices). Optogenetic stimulation of glutamatergic fibers located in the anterior aNAcSh was performed with a $2 \mathrm{~ms}$ pulses at $7 \mathrm{~Hz}$ or just two pulses of $20 \mathrm{~ms}$ width. At the completion of the experiments, slices containing biocytin-injected neurons were fixed by immersion in $4 \% \mathrm{PFA} / 0.5 \%$ glutaraldehyde and stored overnight at $4^{\circ} \mathrm{C}$.

\section{Biocytin histochemistry}

Slices containing biocytin-filled neurons were transferred into 4\% PFA overnight. In some cases, the thick sections were resectioned on a vi-

$\leftarrow$

(Figure legend continued.) the soma of an MSN showing the latency to the first induced action potential (red trace). $\boldsymbol{D}$, Voltage response induced by depolarizing current injection and the action potentials evoked (black trace). In the same neuron, optogenetic activation of terminals ( $2 \mathrm{~ms}$, at $7 \mathrm{~Hz}$ ) evoked a strong depolarization of the MSN that induced action potentials (red traces). $\boldsymbol{E}$, Voltage-clamp recording in another MSN showing that optogenetic activation of terminals (two pulses of light, $20 \mathrm{~ms}$ ), evoked a strong inward current (black trace). In presence of AP5 and CNQX (50 and $10 \mu \mathrm{m}$, respectively), the inward current was markedly inhibited showing that optogenetic activation evokes glutamate release from these glutamatergic terminals. $\boldsymbol{F}$, Top, Responses of a fast spiking interneuron to intracellular current injections (bottom), showing a stuttering pattern of firing (red trace) or high-frequency firing (black trace). $\boldsymbol{H}$, Plot of current-voltage relationship and input resistance of this interneuron. $\mathbf{G}$, Train of action potentials to intracellular current injection (top). The firing frequency was increased after optogenetic stimulation of glutamatergic fibers in the striatum during the train $(2 \mathrm{~ms}$, at $7 \mathrm{~Hz}) . \boldsymbol{I}$, The same single light pulses were enough to depolarize and evoke action potentials at resting membrane potential (bottom). bratome at $100 \mu \mathrm{m}$. Sections were washed for $3 \times 10 \mathrm{~min}$ in $0.1 \mathrm{M}$ phosphate buffer (PB) followed by $10 \%$ methanol and $3 \% \mathrm{H}_{2} \mathrm{O}_{2}$ for 15 min, and incubated with avidin-biotin-peroxidase complex (Vector Laboratories; $1: 200$ ) and $0.1 \%$ Triton X-100 overnight at $4^{\circ} \mathrm{C}$. After washing $6 \times 10 \mathrm{~min}$ in $0.1 \mathrm{M} \mathrm{PB}$, the sections were reacted with $\mathrm{DAB}(0.025 \%)$, and $\mathrm{H}_{2} \mathrm{O}_{2}(0.0008 \%)$ in $\mathrm{PB}$ with nickel intensification (Adams, 1981) was used $(2.5 \mathrm{~mm}$ nickel ammonium sulfate and $7 \mathrm{~mm}$ ammonium chloride in the $\mathrm{DAB}$ and $\mathrm{H}_{2} \mathrm{O}_{2}$ incubation). The slices were mounted and air dried on gelatin-coated slides and then were dehydrated through a graded series of ethanol, followed by xylene. Finally, the slides were coverslipped in Depex (EMS) for their visualization under light microscopy.

\section{Results}

\section{Patch clamping brain slices}

Optogenetic stimulation of glutamatergic axons afferents activates local striatal neurons

To demonstrate that optogenetic stimulation of aNAcSh glutamatergic fibers will evoke action potentials in local MSNs (and presumably in FSIs) (Sciamanna et al., 2015), we performed patch-clamp studies on aNAcSh slices from Thy1-ChR2 mice (Fig. 1A). Figure $1 B$ shows that, in these slices, labeling is abundant in the fibers and excluded from cell bodies. Also shown in Figure $1 C, D$ is that photostimulation of aNAcSh fibers triggers action potentials in morphologically and electrophysiologically identified MSNs. Moreover, these optically evoked excitatory inward currents were inhibited by AMPA and NMDA glutamatergic antagonists (Fig. $1 E$ ). In addition, optogenetic stimulation of glutamatergic inputs also evoked spikes from electrophysiologically identified FSIs (Fig. $1 F-I$ ). These data demonstrate that photostimulation of glutamatergic fibers in the aNAcSh activates local aNAcSh circuitry. Thus, it follows that this optogenetic modulation persists in the following studies with behaving animals.

\section{Behavioral studies}

Photoactivation of glutamatergic aNAcSh fibers stops sucrose intake

We initially characterized how activation of glutamatergic aNAcSh fibers in Thy1-ChR2 mice would affect their consumption of sucrose $(10 \% \mathrm{w} / \mathrm{v})$. This was achieved by designing a task that did not require any formal training because it exploited the natural freely licking behavior of mice and maintained all physiological features of consummatory behavior. The task consisted of three epochs: Baseline epoch, where the animals had to lick four consecutive times; Laser epoch, where the laser was turned on for $1 \mathrm{~s}$ and pulsed at four different frequencies $(4,7,14$, and 20 $\mathrm{Hz}$ ); and a Time out epoch, where the laser was off for at least $1 \mathrm{~s}$ and remained off until the animal recovered to lick four consecutive times (Fig. 2A; see Materials and Methods; Movie 1). Shown in Figure $2 B, C$ are representative raster plots of the licking responses to $10 \%(\mathrm{w} / \mathrm{v})$ sucrose aligned to the time of the first laser activation (time $=0 \mathrm{~s}$ in the Laser epoch) for wild-type (WT) and Thy1-ChR2 mice, respectively. For the Thy1-ChR2 mice, the higher the frequency, the fewer the number of licks and, consequently, the smaller the sucrose consumption (Fig. 2C). These responses do not occur in WT mice. Figure $2 D$ shows the quantification of this effect for each group. A two-way ANOVA found a significant main effect for group: $F_{(2,8)}=614, p<0.0001$ and for laser frequency, $F_{(4,8)}=36.7, p=0.0001$, with a significant interaction between groups and frequency, $F_{(8,4802)}=64.8, p<$ 0.0001 . A post hoc analysis revealed, in comparison with both the $\mathrm{WT}(p<0.0001)$ and WT + Laser $(p<0.0001)$, that the Thy1ChR2 mice transiently stopped licking in a frequency-dependent manner (all $p$ values $<0.001$ ). The response plateaued between 14 and $20 \mathrm{~Hz}$ because there were no significant differences between 
A
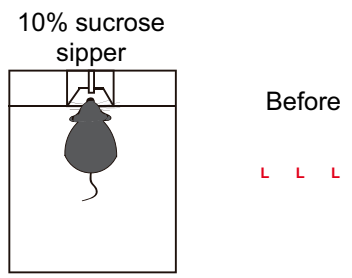

Single trial

B

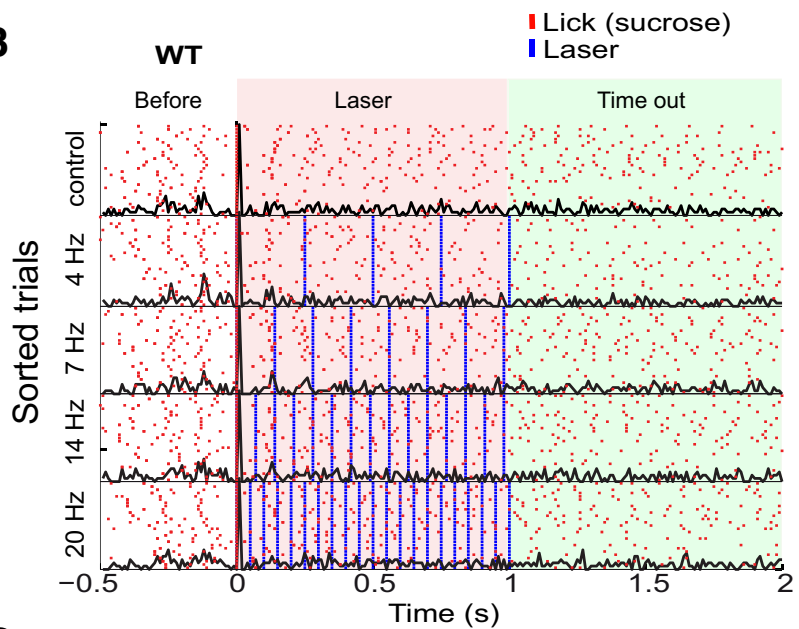

C

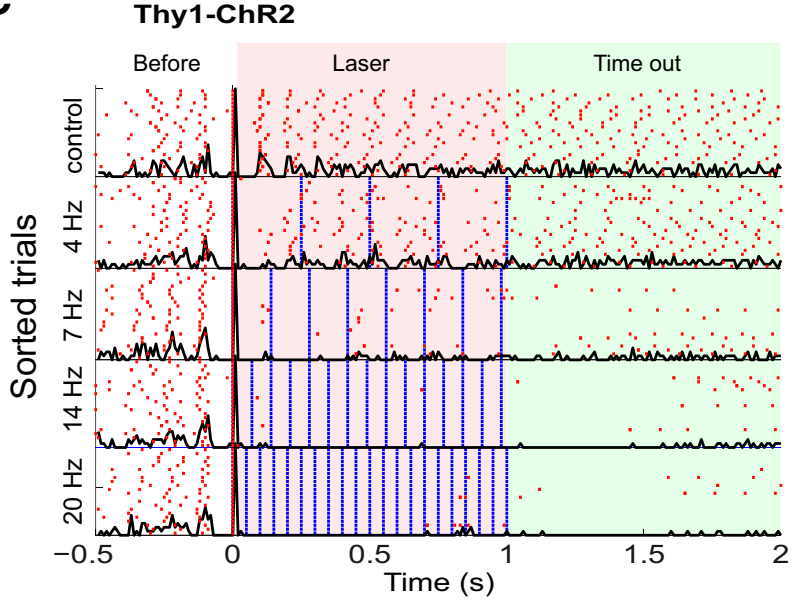

G

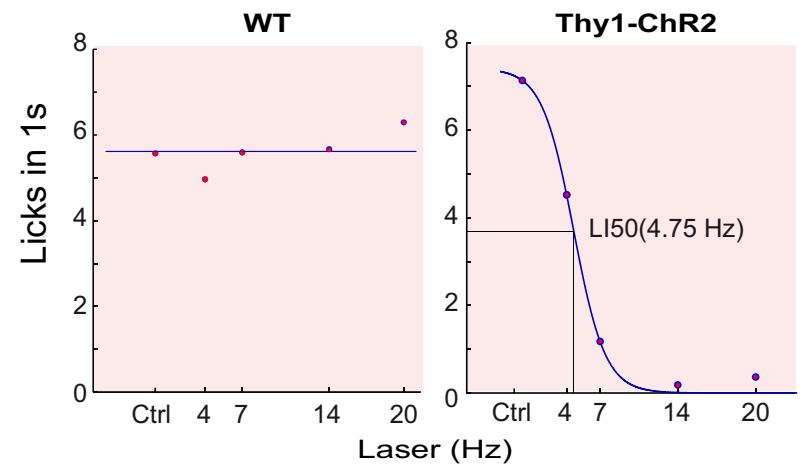

New trial

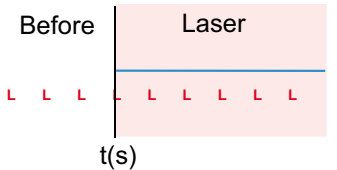

$t(s)$

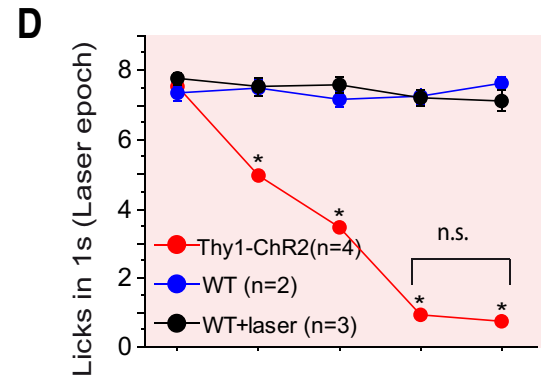

E

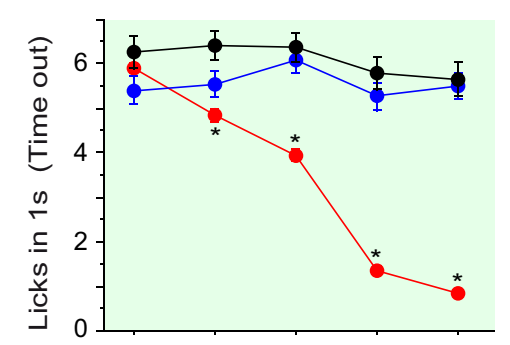

F

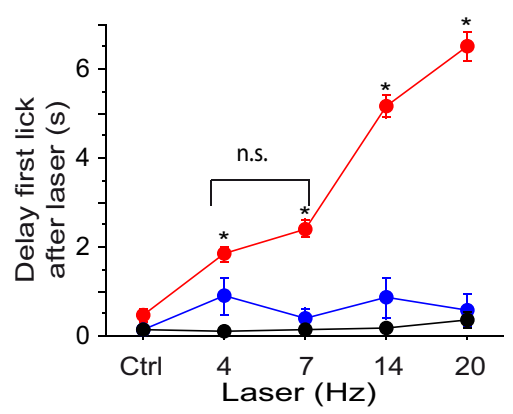

Figure 2. Global optogenetic stimulation of aNACSh fibers transiently stops sucrose consumption and delays resumption of sucrose intake. $A$, The closed-loop freely licking task contains three epochs: Before (four licks), Laser (1 s), and Time out (1s). For more details, see Materials and Methods. Each red "L" indicates a lick given to a sipper filled with a solution of $10 \%$ sucrose. Every four licks given right after the Time out epoch initiate a new Laser epoch. Thus, mice have a direct control over the number of trials and laser stimulation (but not the frequency they receive). $B, C$, Representative raster plots of licking responses (red ticks) of WT and Thy1-ChR2 licking responses aligned at time $=0$ s to the aNAcSh's photostimulation as a function of laser frequency. Optical stimulation in the Thy1-ChR2, but not in the WT mice, rapidly stops licking for sucrose. For an example of this behavior, see also Movie 1.D, Graph showing the number of licks in the $1 \mathrm{~s}$ window of the Laser epoch (1 s). E, The Time out epoch. $\boldsymbol{F}$, Plot of the delay to the first lick after first laser pulse. G, The $\mathrm{L}_{50 \%}$ value (a measure of the overall sensitivity to photostimulation) was computed from the licking rate during the Laser epoch, as a function of laser's frequency. Left, $\mathrm{L}_{50 \%}$ of the raster plot shown in B. Middle, Thy1-ChR2 mice shown in C. Rightmost panel, Plot of the average $\mathrm{L}_{50 \%}$ value for each group. Each dot indicates the average $\mathrm{L}_{50 \%}$ across all days tested for each subject. Thy1-ChR2 mice displayed different sensitivity levels, but their $\mathrm{L}_{50 \%}$ values remained constant across stimulation days (data not shown). 
A

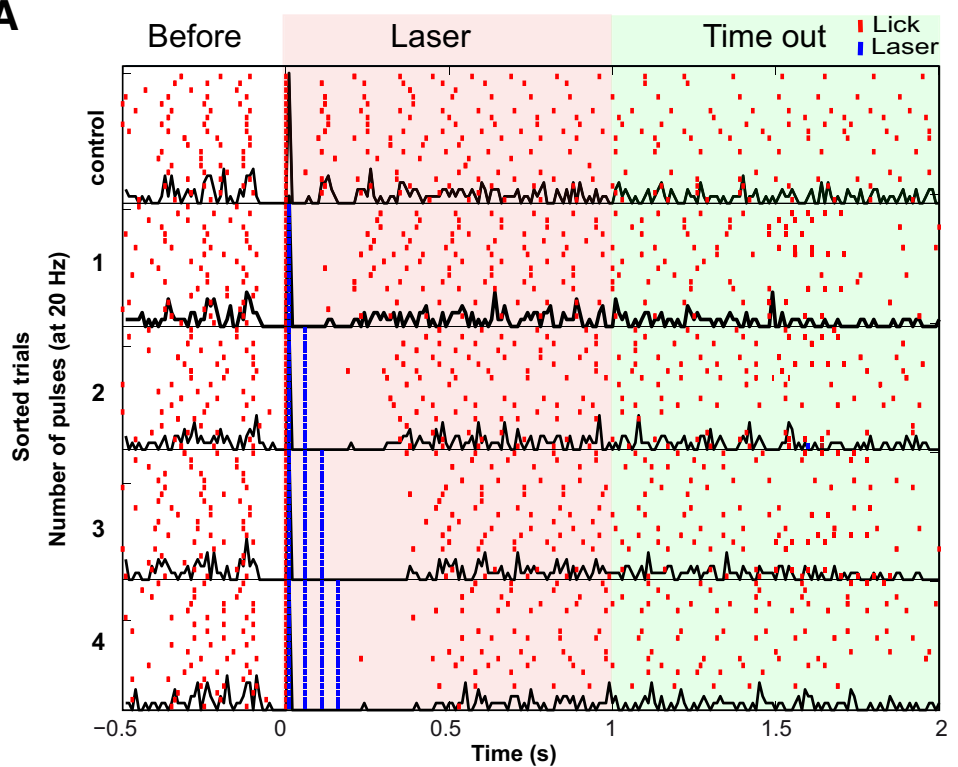

B

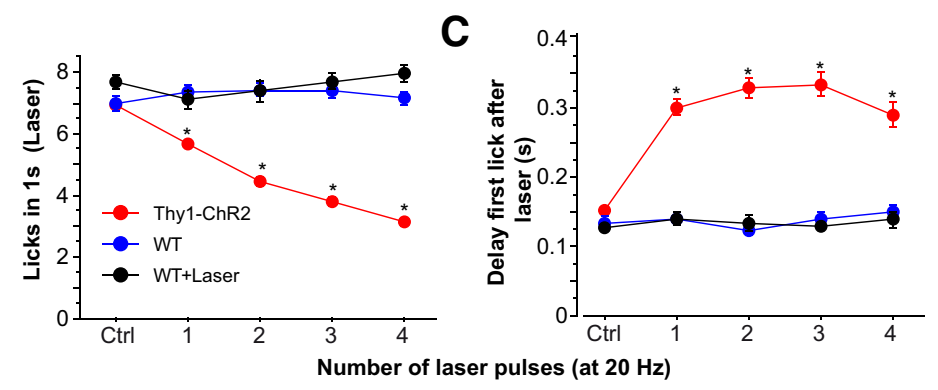

Figure 3. A single light pulse was sufficient to transiently refrain animals from licking for sucrose. $A$, The task was identical to that displayed in Figure 2A, except that photostimulation only comprised 0 (Ctrl = control), 1, 2, 3, or 4 blue light pulses ( $30 \mathrm{~ms}$ width each pulse) delivered at a $20 \mathrm{~Hz}$ frequency. Shown is a raster plot for licking (red ticks) aligned (time $=0$ ) to light flashes (blue marks). $\boldsymbol{B}$, Lick rate during the Laser epoch as a function of group. C, Delay (in seconds) for the first lick given after the first laser pulse. This analysis uncovered that all laser pulses delayed resumption of licking relative to control trials.

these frequencies ( $p=0.41$, not significant; Fig. $2 D$ ). To quantify the stimulation frequency dependence on licking for Thy1-ChR2 mice, the data were fit to a sigmoidal function that yielded a value of $4.75 \mathrm{~Hz}$ for the $50 \%$ licking inhibition $\left(\mathrm{LI}_{50 \%}\right)$. In contrast, at all tested frequencies, the WT mice were unaffected by optical stimulation (Fig. 2G). In summary, these data show that, even though the mice were food- and water-deprived for $12 \mathrm{~h}$, unilateral optogenetic stimulation of glutamatergic aNAcSh fibers transiently stopped the Thy1-ChR2 mice licking for sucrose.

In the Time out epoch, it is seen that for Thy1-ChR2, but not WT mice, the higher the stimulation frequency, the fewer the number of licks (Fig. 2E) and the longer the delay to the next lick (Fig. 2F). Finally, in Movie 1, the behavioral effect induced by the optogenetic stimulation on sucrose consumption can be clearly seen. Activation of glutamatergic fibers rapidly stops licking for sucrose (most readily seen at higher frequencies), and upon stimulation, mice switched their behavior from licking for sucrose to exploring the behavioral box and/or grooming.

One single light pulse (30 ms) was enough to transiently interrupt sucrose consumption

In the same group of animals, we also characterized the number of $20 \mathrm{~Hz}$ laser pulses that were necessary for the mice to stop licking for sucrose. In an abridged version of the above-described task, animals received trials with no-stimulation (Control) or trials with 1, 2, 3, or 4 laser pulses. Interestingly, it was found that only a single optical pulse was sufficient to transiently interrupt their licking for sucrose (Fig. 3A; [two-way ANOVA; effect of group $F_{(2,8)}$ $=278, p<0.0001$ and effect of light pulses, $F_{(4,8)}=6.1, p=0.0001$, with a significant interaction between groups and pulses, $\left.\left.F_{(8,2217)}=23.4, p<0.0001\right]\right)$. However, stimulating for the entire $1 \mathrm{~s} \mathrm{ep}$ och was more effective in stopping licking (compare Fig. $2 D$ vs Fig. $3 B$ ). These results, summarized in Figure $3 B$, show that, relative to both control groups, for Thy1-ChR2 mice their licking rate was significantly decreased (all $p$ values $<0.0001$ ) in a manner that depended on the number of pulses (all $p$ values $<0.01)$. Likewise, compared with WT and $\mathrm{WT}+$ laser treated mice, for the Thy1-ChR2 mice, one laser pulse significantly delayed resumption of licking for sucrose (Fig. 3C; [two-way ANOVA; effect of group $F_{(2,8)}=120.6, p<0.0001$ and effect of light pulses, $F_{(4,8)}=3, p=$ 0.017 , with a significant interaction between groups and number of pulses, $F_{(8}$, 2217) $=6.37, p<0.0001]$ ). In summary, stimulation of glutamatergic fibers in the aNAcSh transiently stopped animals licking for sucrose.

\section{Thy1-ChR2 mice learn to lick an empty sipper to self-photoactivate glutamatergic afferents in the aNAcSh}

Given that aNAcSh stimulation transiently stopped animals feeding for a hedonically positive stimulus like sucrose, we next asked whether a taste stimulus is even necessary and if they would selfstimulate for what may be interpreted to be an apparently aversive behavior (licking an empty sipper). Using the same task as described above, we tested a new group of sucrose-naive mice initially for $7 \mathrm{~d}$, only here the animals had to lick an empty sipper (Fig. 4A, left and middle columns). This sequence was followed by 3 more days of testing where the sipper contained $10 \%(\mathrm{w} / \mathrm{v})$ sucrose (Fig. 4A, right column). Representative raster plots illustrating the licking responses aligned to laser onset for a WT (top) and Thy1-ChR2 mouse (bottom). As evidenced in the raster plots shown, WT mice normally avoid licking an empty sipper (Perez et al., 2013). For example, note the few number of trials given on days 1 and 5, whereas the same mouse will avidly lick a sipper containing sucrose (day 10). For the WT mice, this behavior is independent of aNAcSh stimulation. In contrast, the Thy1-ChR2 mouse learned to avidly lick an empty sipper (compare controls at days 1 and 5) and, of course, on day 10 avidly licked for sucrose. As expected, when they were optically stimulated, the Thy1ChR2 mice stopped licking.

For the Thy1-ChR2 mice, the quantification of learning to lick an empty sipper and that the activation of glutamatergic aNAcSh fibers are not aversive, but rewarding (at least, in the sense of learning and wanting) (Berridge et al., 1997), is shown in the plot of mean responses across days (Fig. 4B). For the WT mice, the 
A
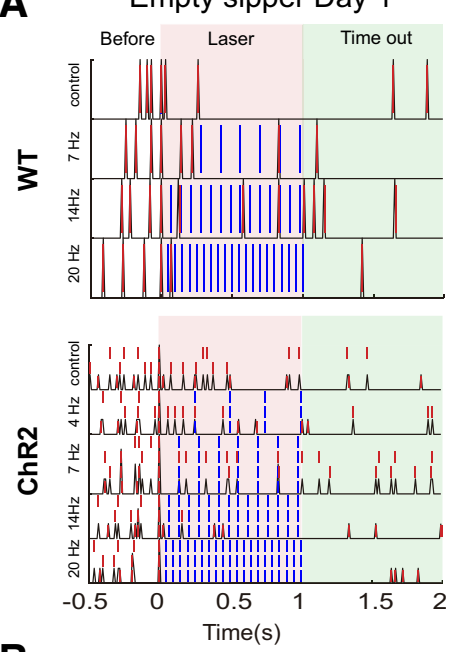

Empty sipper Day 5
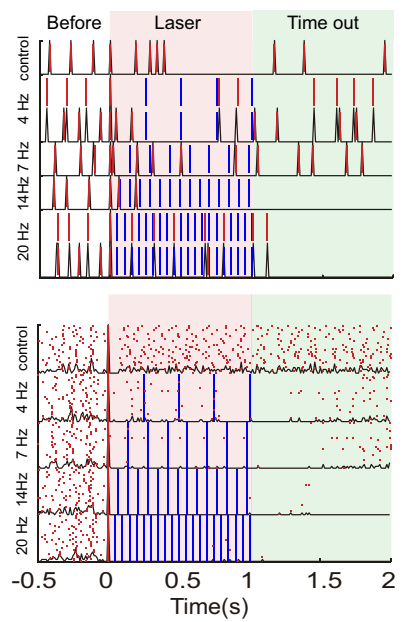

Sucrose Day 10
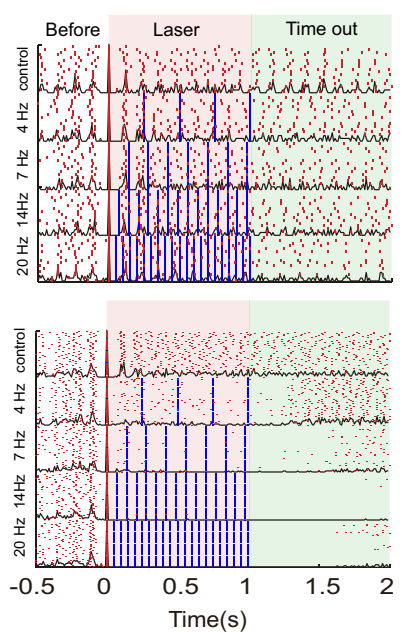

Sucrose

D

I Lick
ILaser
B
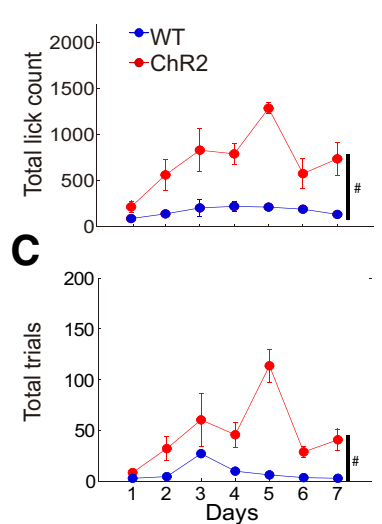
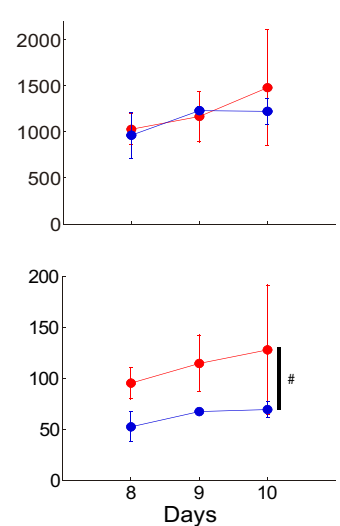
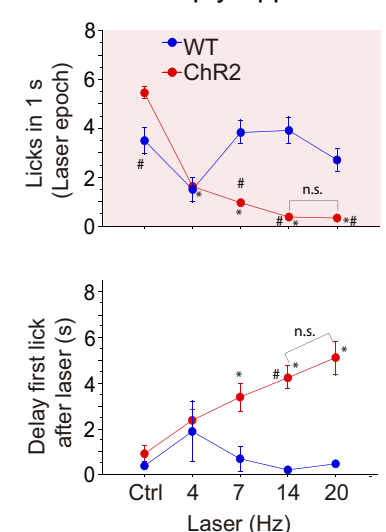

Sucrose

Figure 4. Thy1-ChR2 mice lick an empty sipper to self-photoactivate aNACSh fibers. $A$, Representative raster plots of WT (top rows, $n=3$ ) and transgenic mice (bottom rows, $n=3$ ) with animals licking an empty sipper (left and middle columns) or sessions with a sipper filled with sucrose (right column). Each raster represents the licking responses (red ticks) aligned to the photostimulation of the aNACSh (time $=0$ ) as a function of laser frequency (shown in blue ticks). $\boldsymbol{B}$, The chronological order of the experiments and the number of licks given to an empty sipper across $7 \mathrm{~d}$ (sessions 1-7) of photostimulation, followed by 3 more sessions (sessions $8-10$ ) with a sipper filled with sucrose. $\boldsymbol{C}$, Same as $\boldsymbol{B}$, but plots the number of trials per session. $\boldsymbol{D}$, The number of licks in the $1 \mathrm{~s}$ window of Laser epoch given when licking an empty sipper (left) and with a sipper filled with $10 \%$ sucrose (right). Bottom, Delay to the first lick after first laser pulse. * $p<0.05$ relative to control trials. ${ }^{p} p<0.05$ in comparison with the WT mice.

total number of licks across days (all trials included) and trials (the number of "Before" events) were low and relatively constant. However, for the Thy1-ChR2 mice, both the number of licks and trials markedly increased until day 5 and then decreased for the remaining 2 testing days. Although we do not understand why self-stimulation did not follow a linear growth pattern, we found that animals continued on days 6 and 7 to significantly lick more than the WT mice (ANOVA, $F_{(1,10)}=8.1, p=0.017$ ). Because a taste stimulus was not present (and hence there was no "liking" component of reward, unless it is pleasant to stop empty licking), the increased number of licks and trials indicate that the ThylChR2 animals learned to lick the empty sipper to self-stimulate glutamatergic inputs, suggesting that the stimulation is rewarding, at least in the sense of wanting. Significant differences were found across the 7 testing days between the number of licks and trials between the WT and Thy1-ChR2 mice (repeated-measures ANOVA factor WT vs Thy1-ChR2; $\left.F_{(1,24)}=36.44 ; p<0.005\right)$. These same animals were again tested on days $8-10$ (right panels), only now with the sippers containing sucrose. In these sessions, both WT and Thy1-ChR2 mice produced the same number of licks (i.e., consumed the same amount of sucrose; repeatedmeasures ANOVA, $\left.F_{(1,8)}=0.215 ; p=0.66\right)$, indicating that
aNAcSh stimulation did not diminish their hunger or affect the palatability of sucrose. However, to achieve the same amount of sucrose intake as the WT animals, the Thy1-ChR2 mice performed significantly more trials (repeated-measures ANOVA, $\left.F_{(1,8)}=8.69 ; p<0.05\right)$.

In addition, for both mouse types, we analyzed, as a function of laser frequency, the licks in the Laser epoch and the delay to the first lick after first laser pulse. As seen in Figure $4 D$, for the Thy1ChR2 mice, as expected, the number of licks decreased with increasing frequency for both the empty and the sucrose containing sipper. The $\mathrm{LI}_{50 \%}$ for the empty sipper versus sucrose sessions were not significantly different (Empty sipper: $\mathrm{LI}_{50 \%}=5.4 \pm 1.4$, $n=15$; Sucrose sipper: $\mathrm{LI}_{50 \%}=2.5 \pm 0.4 ; t$ test $p=0.14, n=8$; data not shown), indicating that, regardless of caloric content (at least for sucrose), stimulation of aNAcSh fibers transiently stopped licking. The bottom panels show the delay to the first lick after first photostimulation pulse. It is seen that, in both cases, the transgenic mice delayed resumption of licking as a function of stimulation frequency. In sum, these data suggest that activation of aNAcSh glutamatergic fibers is rewarding, at least in the sense of wanting and learning, and it transiently stops licking regardless of caloric content and hedonic content of sucrose. 
A

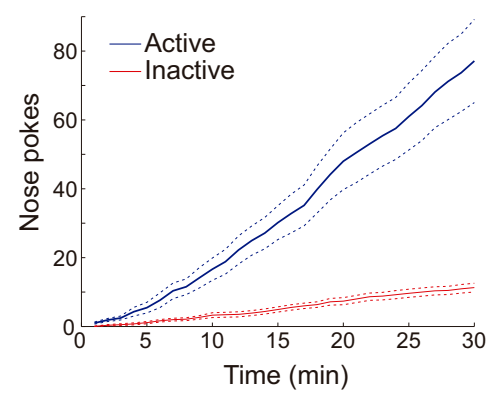

B

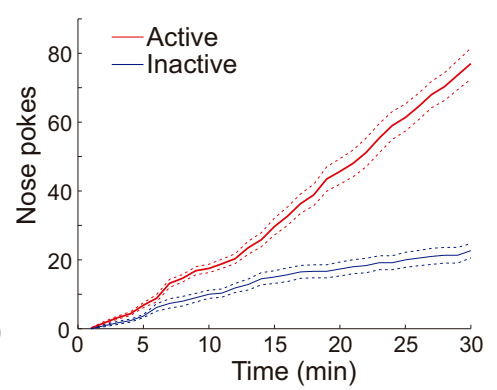

Figure 5. Activation of glutamatergic fibers of the aNACSh is rewarding. $\boldsymbol{A}$, Graph showing the cumulative number of nose-pokes performed in a 30 min session, the position of the Active and Inactive ports was counterbalanced. In this close-loop task, every nose poke given to the Active port (blue trace) triggered a $1 \mathrm{~s}$ train of optical stimulation at $20 \mathrm{~Hz}$, whereas a nose-poke in the Inactive port (red trace) had no programmed consequence. Note how transgenic Thy1-ChR2 mice nose-poked to self-stimulate glutamatergic inputs of the aNACSh. $\boldsymbol{B}$, Once animals maintained a constant rate of self-stimulation for at least four sessions, the positions of the Active and Inactive ports were switched. Animals stopped responding to the previously reinforced Active port (blue trace), and they began responding to the new position of the Active port (red trace). Also see Movie 2 for an example of this behavior.

To further demonstrate that optical stimulation of glutamatergic afferents are per se rewarding, independent of their ability to stop licking, we tested a new set of transgenic mice using a different behavior (other than licking an empty sipper) to selfstimulate. In this task, transgenic mice were allowed to nose-poke to trigger a $1 \mathrm{~s}$ train of laser stimulation (at $20 \mathrm{~Hz}$ ). We found that these mice learned to avidly nose-poke the Active port and basically neglected the Inactive port (Fig. 5A; Kolmogorov-Smirnov test $=261 ; p<0.0001)$. To demonstrate that these responses were not random, the positions of the Active and Inactive port were switched (Fig. 5B) whereupon these animals rapidly stopped responding to the previously Active port (data not shown) and after 3-4 d they relearned and began responding to the new position of the Active port (Kolmogorov-Smirnov test = $60.8 ; p<0.0001$; see also Movie 2). We take these data as evidence that a $20 \mathrm{~Hz}$ activation of glutamatergic fibers is rewarding in Thy1-ChR2 mice, regardless of the fact that it stops licking.

Open-loop optical stimulation of aNAcSh fibers stops sucrose feeding, but it does not decrease overall sucrose intake

With a new group of both WT and Thy1-ChR2 mice $(n=3$ per group), we tested whether prolonged stimulation of aNAcSh fibers would decrease their intake of sucrose. This test consisted of three 5 min blocks of pulsed laser activation, independent of the animal's behavior (i.e., regardless of whether the animal was feeding) that were separated by 5 min unstimulated blocks. Figure $6 A$ shows the total number of licks in each 5 min block. It is seen that initially the stimulated WT mice avidly licked for sucrose but, as expected, the number of licks/block monotonically decreased until the animals became sated (Fig. 6, black circles). In contrast, the Thy1-ChR2 mice exhibited a marked reduction in licking in the initial laser 5 min stimulation block. However, during the first and second unstimulated blocks (Fig. 6A, red circles; 5-10 min and 15-20 $\mathrm{min}$ ), the animals greatly increased their intake of sucrose (arrows). This increase in sucrose intake was significantly greater than for the WT mice (post hoc WT vs Thy1-ChR2 in block 2; $p<0.001$ ). However, by the end of the session, both mouse types licked (ingested) approximately the same amount of sucrose [a repeated-measures ANOVA of all blocks found a nonsignificant effect for type of mice; $F_{(1,4)}=0.2, p=0.66$, but significant effect for the factor block $\left(F_{(1,4)}=11.4, p<0.0001\right)$ with a significant interaction type of mice $\times$ block $F_{(1,6)}=9, p<$
0.0001]. These data indicate that prolonged stimulation of glutamatergic inputs does not overtly affect the state of hunger/satiety of animals.

The accelerated intake of sucrose is more clearly seen in the minute-by-minute cumulative licking distribution shown in Figure $6 B$, whereas, for the WT mice, the rate of change of sucrose intake decreased smoothly and monotonically until satiety, the Thy1-ChR2 mice exhibited a very different behavior. Specifically, in the first photostimulation block (blue shadings, $0-5 \mathrm{~min}$ ), the comparatively small number of licks increased slowly until the subsequent $5 \mathrm{~min}$ unstimulated block (Fig. 6B, interval 5-10 min) where they licked at an accelerated rate, which leveled off in the second stimulated block (interval 10-15 $\mathrm{min}$ ) and then increased again in the second unstimulated block. The cumulative licking distribution between the WT and Thy1-ChR2 mice was significantly different (Kolmogorov-Smirnov test $=0.355, p=$ 0.029).

The accelerated intake of sucrose observed in the Thy1-ChR2 could arise from the prolonged activation of aNAcSh fibers that, upon after stopping stimulation, triggered a rebound activity in the aNAcSh or as a behavioral strategy to compensate for the "lost time" in feeding that was not directly caused by the optogenetic stimulation (see below and Discussion).

\section{The neuronal correlates in the aNAcSh during the open-loop stimulation task}

To test these two alternatives and to obtain the neuronal correlates of this stimulation task, we performed optrode recordings in the aNAcSh during the prolonged 5 min stimulation open-loop task (Fig. $6 C-E$ ). In a new group of transgenic mice $(n=5)$, we recorded a total of 182 single neurons. Figure $6 C$ shows the raster plot and PSTHs (below) displaying the responses of two representative single neurons: one activated (top) and the other inhibited (bottom) after optical stimulation of glutamatergic inputs. The upper raster shows a neuron that fired coherently with each laser pulse (at $20 \mathrm{~Hz}$; blue ticks represents a single spike; from 0 to $1 \mathrm{~s})$, but relative to baseline (BL) and the three unstimulated blocks (Off, black spikes), this neuron also increased its firing rate during the $2 \mathrm{~s}$ Time out epoch. The other example (bottom raster) also showed a response that was coherent with laser stimulation, but in the $2 \mathrm{~s}$ Time out epochs its overall activity decreased (Fig. 6C, bottom raster; compared black vs blue PSTHs). We also recorded neurons that exhibited a strong inhibition that persisted the entire 5 min stimulation block (Fig. 6E, neurons 180-182).

As expected, optical stimulation of glutamatergic inputs strongly activated the population activity of the aNAcSh, but this response was restricted to the actual $1 \mathrm{~s}$ of stimulation, as clearly seen when responses were aligned to the first laser pulse (Time $=0$ s; Fig. $6 D$ ). From this point forward, its magnitude decreased with subsequent laser pulses until the fourth pulse whereupon it remained constant until the last delivered light pulse (see the 3 overlap blue traces, one for each block, in Fig. 6D). During the $2 \mathrm{~s}$ of the Time out epoch (from 1 to $2 \mathrm{~s}$ and -1 to $0 \mathrm{~s}$ ), and relative to baseline activity level $(\mathrm{BL}=0 Z$-score), the overall population activity was significantly less. It is important to note that the population activity remained relatively unchanged across the three unstimulated blocks (see black 
A

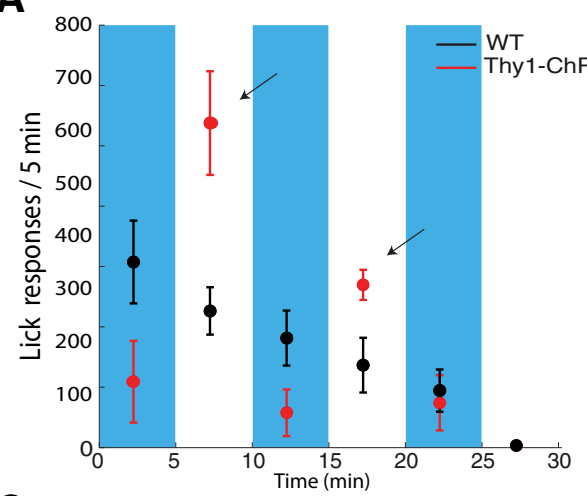

C

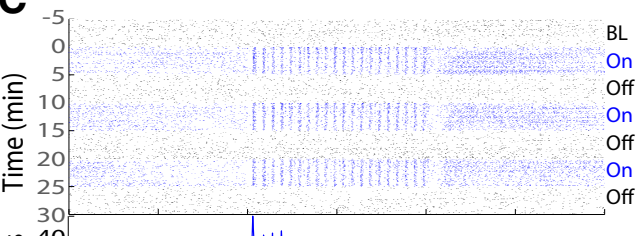

气̊
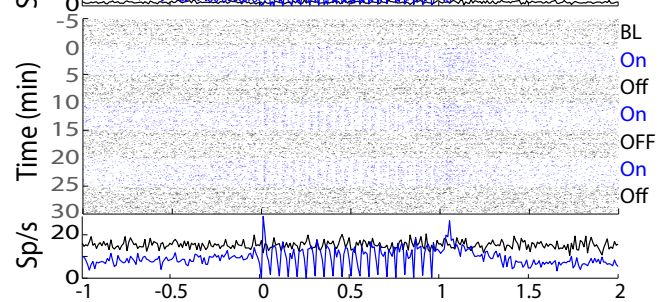

D

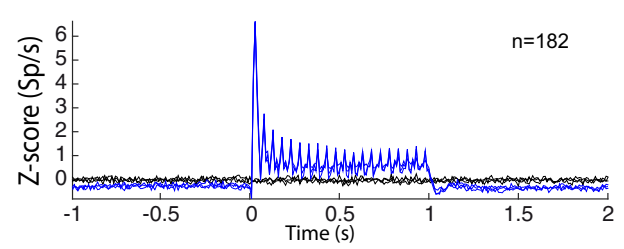

B
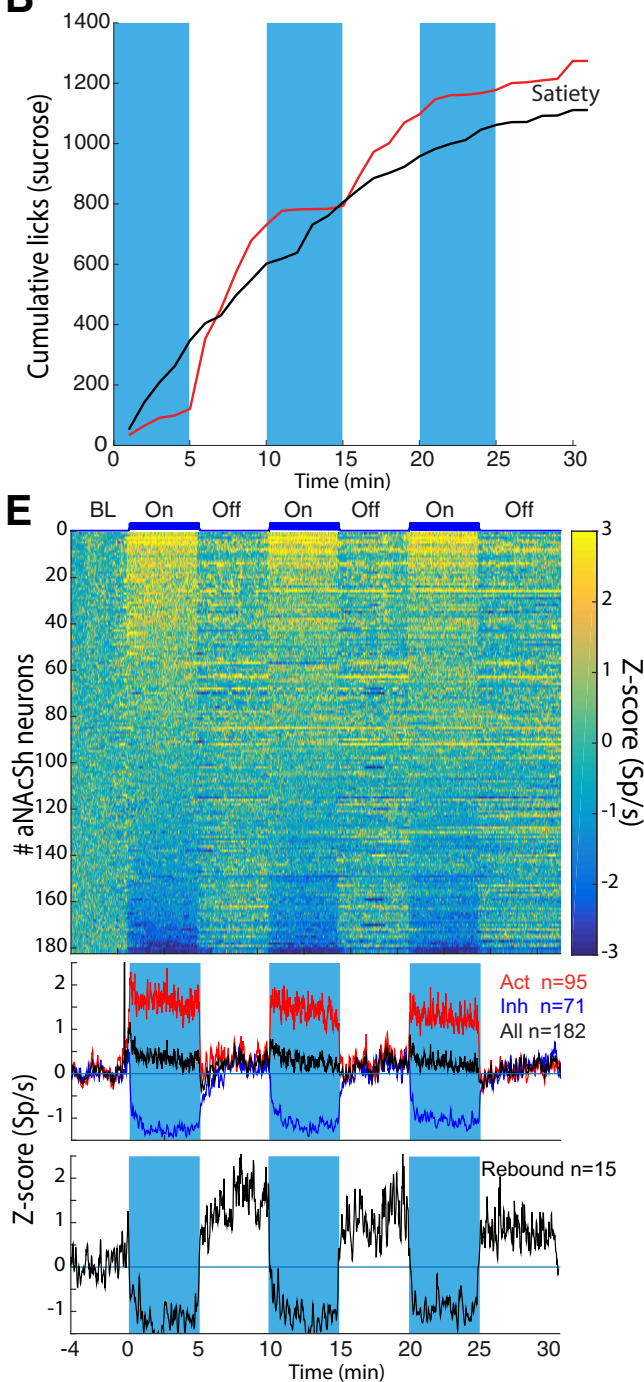

Figure 6. Optical stimulation of aNAcSh fibers transiently stops sucrose feeding, but it does not decrease overall intake. $A$, Plot of the number of licks in stimulated 5 min blocks (blue shading represents $20 \mathrm{~Hz}$, 1 s on and $2 \mathrm{~s} \mathrm{time} \mathrm{out} \mathrm{where} \mathrm{the} \mathrm{laser} \mathrm{was} \mathrm{off)} \mathrm{separated} \mathrm{by} 5$ min unstimulated blocks for WT ( $n=3$, black) and Thy1-ChR2 mice ( $n=3$, red). B, Cumulative intake of sucrose across the 30 min session. Arrows indicate periods where transgenic mice experienced an increase in wanting for sucrose. At the end of the session, they ingested approximately the same amount of total sucrose, indicating that activation of these fibers does not induce satiety. C, Optrode recordings in the aNACSh while a new set of transgenic mice performed the open-loop stimulation task. Raster plot of two neurons recorded: one activated and the other inhibited by the stimulation. Responses were aligned (time $=0$ ) to the onset of a $20 \mathrm{~Hz}(1 \mathrm{~s}$ on $2 \mathrm{~s} \mathrm{time} \mathrm{out)} \mathrm{photoactivation} \mathrm{train}$ of glutamatergic inputs of the aNACSh. Thus, responses during the -1 to 0 and 1 to $2 \mathrm{~s}$ correspond to the $2 \mathrm{~s}$ time out periods. In the $y$-axis (from top to bottom), trials were plotted in chronological order so the first 100 trials belong to the first -5 to 0 min baseline epoch (BL) block, where sucrose was not available. At time 0 min, sucrose was made available; thus, times $0-5,10-15$, and $20-25$ min correspond to the three 5 min stimulated blocks ( $0 \mathrm{n}$ ), whereas the interleave trials belong to the three unstimulated blocks (0ff). The spikes are shown in black ticks for unstimulated ( $0 \mathrm{ff}$ ) blocks and in blue ticks for stimulated ( 0 n) blocks. For visualization purposes, neither licks nor laser ticks are shown. Top raster, The neuron increased its firing rate during the entire 5 min stimulated blocks. This was due to the increased in firing during the laser frequency (time $=0-1 \mathrm{~s}$ ) and during the $2 \mathrm{~s}$ time out period (more easily seen in time $=1-2 \mathrm{~s}$ ). Activity returned to baseline levels in the unstimulated blocks (see black PSTHs, below). Bottom raster, Neuron that, even when it responded coherently with laser pulses (time $0-1 \mathrm{~s}$ ), it was inhibited during the stimulated block. This is because the neuron decreased its firing rate during the $2 \mathrm{~s} \mathrm{time} \mathrm{out} \mathrm{period} \mathrm{(E,} \mathrm{blue} \mathrm{trace,} \mathrm{Inh} \mathrm{responses).} \boldsymbol{D}$, Normalized Z-score population response of all 182 aNAcSh neurons aligned to laser onset for stimulated blocks (blue trace) and to arbitrary trials (3 s chunks) in the unstimulated block (black trace).E, Color-coded Z-score PSTH for all 182 neurons recorded in the task. Responses were sorted using the population PCA analysis; thus, neurons in the top were activated and at bottom inhibited during stimulation of glutamatergic inputs. Bottom, Population PSTH of all active neurons (red trace) and inhibited responses (blue) and population of all neurons recorded (black trace). Responses tend to return to baseline activity during the unstimulated blocks, so the overall activity of the aNAcSh returned to baseline levels; thus, it did not correlate with the acceleration in sucrose intake observed in the unstimulated blocks (see $\boldsymbol{A}$ ). Bottommost panel, Activity of a small subset of neurons $(n=15)$ that displayed a selective rebound activity during the unstimulated blocks. This rebound activity was stronger in the first and second unstimulated blocks where mice tended to accelerate the sucrose intake ( $\boldsymbol{A}$, arrows).

PSTHs), suggesting that it did not track the behavioral acceleration of licking for sucrose (see below) or did the electrophysiological responses track the behavioral changes associated with the animal's approach to satiety.

The electrophysiological recordings, however, did yield insights into the firing rate homeostasis in the aNAcSh. The same neuronal responses, but at a larger macroscale (minutes), were sorted according to the PCA analysis as a function of their modulation (Fig. 6E). Relative to baseline, the bright yellow to dark blue shows more and less activity, respectively. Below is the $52 \%$ (95 of 182) of the neurons that significantly increased their firing rate (see red trace), and the $39 \%$ ( 71 of 182) that decreased their firing rate during the stimulated blocks (see blue trace). In sum, the population activity of all neurons recorded slightly increased 
A

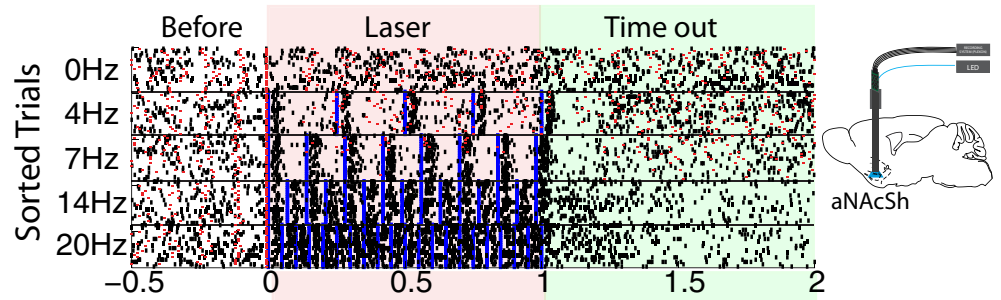

B

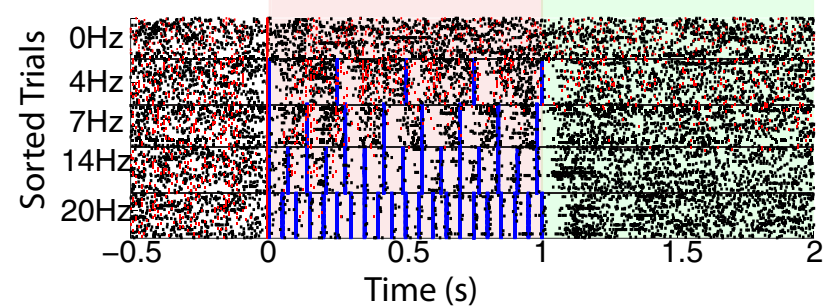

C
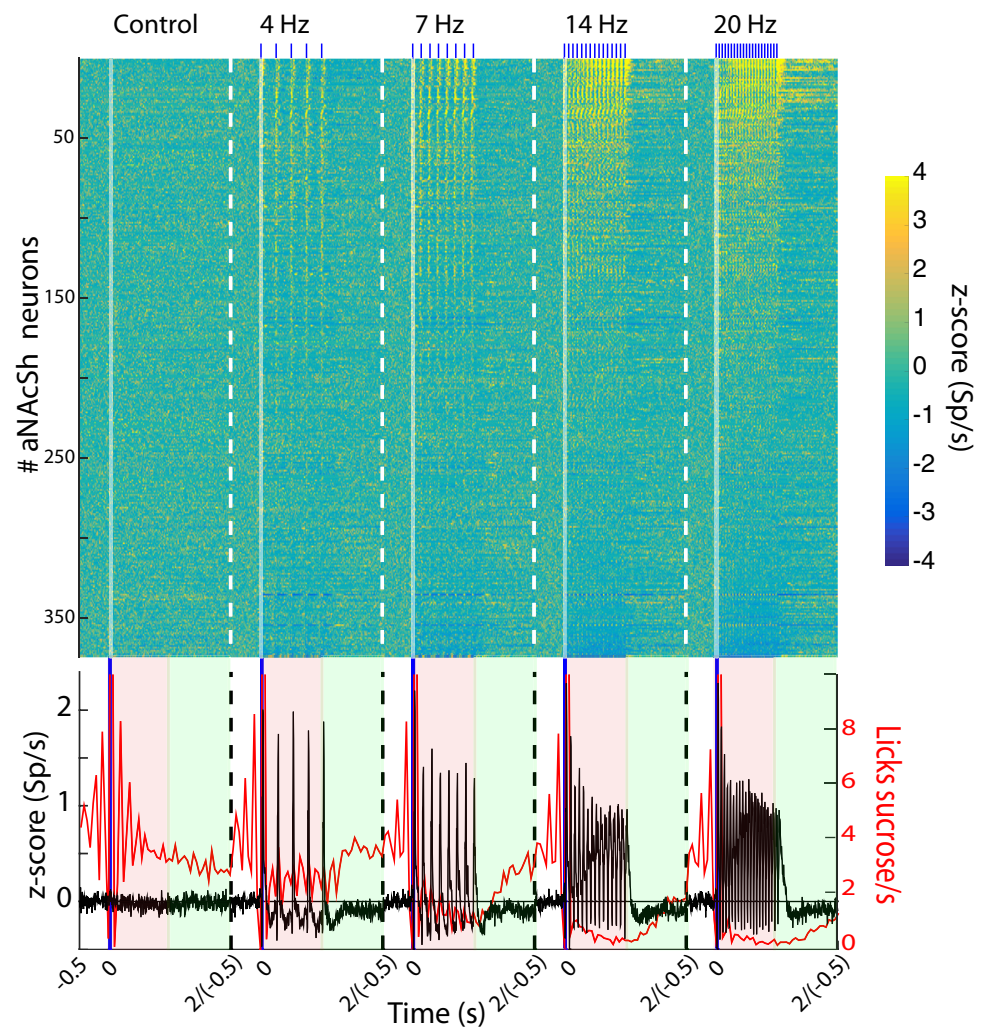

D

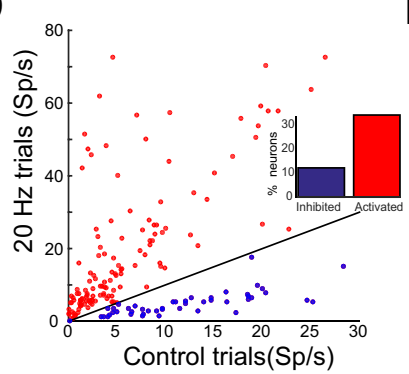

E

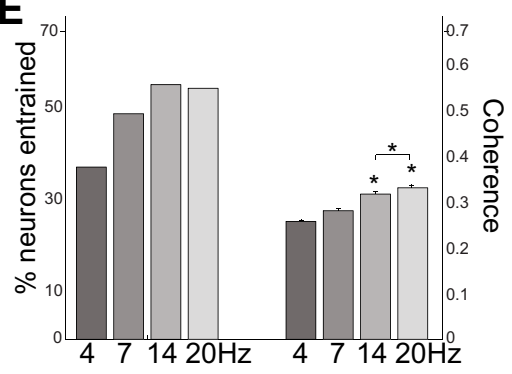

Figure 7. Optogenetic stimulation of aNACSh fibers activates local aNACSh neurons and stops sucrose feeding. $A$, Raster plot of a representative aNAcSh neuron during the Baseline, Laser, and Time out epochs (Figs. 2-4). This neuron fired, at all frequencies, coherently with the photostimulation. Spiking responses were aligned to the first laser pulse (time $=0 \mathrm{~s}$ ) and sorted as a function of laser frequency. Red tick represent a lick given to a sipper filled with sucrose. Black ticks represent single action potentials. The inhibition in the Time out epoch delayed at the higher stimulation frequencies. Right, Inset, Scheme of an optrode implanted in the aNACSh. $\boldsymbol{B}$, Representative example of a neuron whose firing rate was inhibited by optical stimulation. The effect is most easily seen at the higher stimulation frequencies. In the Time out epoch, this neuron recovered rapidly. C, Z-score PSTH for all 381 neurons recorded in the licking task in the Baseline, Laser, and Time out epochs. The neurons ( $y$-axis) were sorted as a function of the first only 0.5-1 SD above baseline levels. Moreover, in the unstimulated blocks, the population activity rapidly returned to baseline (Fig. $6 E$, black trace). These data indicate that the network properties of the aNAcSh exhibit a strong firing rate homeostasis that maintains the spiking activation/inhibition balance, even in the presence of prolong optogenetic perturbation of glutamatergic inputs. It therefore follows that prolonged optogenetic stimulation does not cause a strong rebound in activity in the unstimulated blocks; indeed, it was only observed in 15 neurons (Fig. 6E, bottommost panel). Together, these data suggest that the accelerated increase in sucrose intake is more likely a behavioral strategy of the animal to compensate for the "lost time in getting the available reward," than a side effect of prolonged optogenetic stimulation in the aNAcSh.

\section{Electrophysiological recordings from the aNAcSh, mPFC, and LH in the closed-loop stimulation task}

Optogenetic activation of aNAc's afferents reliable drives activity in local neurons recorded in the aNAcSh

Once the neuronal correlates of the openloop task were characterized, we then obtained the neural correlates in the closeloop task of the behavioral responses that transiently stopped the animals licking for sucrose (Figs. 2-4). To accomplish this, we recorded single units under the same conditions initially in the aNAcSh, an area involved in reward and feeding (Kelley and Berridge, 2002). A total of 381 single neurons were recorded during 56 sessions from 5 male Thy1-ChR2 mice (the responses of all neurons recorded are shown in Fig. $7 C$ ). Figure $7 A$ shows two representative examples of laser-evoked responses from the aNAcSh. In one type, action po-

$\leftarrow$

PCA scores (see Materials and Methods). $x$-axis indicates the binned ( $50 \mathrm{~ms}$ ) neuronal responses $(\sim-0.5$ to $2 \mathrm{~s})$. The photostimulation onset is at time $=0 \mathrm{~s}$. The Z-score PSTHs for control and 4, 7, 14, and $20 \mathrm{~Hz}$ trials were concatenated and displayed as a single PSTH for each recording sessions. Bottom, Population Z-score PSTH of all neurons (activated and inactivated) recorded in the aNACSh (black trace). The licking rate is shown in red (right axis). The average $\mathrm{LI}_{50 \%}$ was $6.57 \pm 0.62$ $\mathrm{Hz}$ for $n=56$ sessions. D, Scatter plot of the firing rate in the Laser epoch during both Controls versus $20 \mathrm{~Hz}$ trial types. Neurons depicted in red were activated by the photostimulation and those in blue inhibited. Inset, Percentage of neurons with a significant modulation. $\boldsymbol{E}$, The percentage of neurons that were significantly entrained for each laser frequency as determined by a coherence analysis (see Materials and Methods). Right, Average coherence value as a function of laser frequency. *Significant with $p<0.05$. 
tentials were evoked in phase with each laser pulse to $20 \mathrm{~Hz}$ (Fig. $\left.7 A ; \mathrm{LI}_{50 \%}=5.9\right)$. In the Time out epoch, the activity remained inhibited as is readily observed in the 14 and $20 \mathrm{~Hz}$ trials. The second, albeit less common, type of response, shown in Figure $7 B$, revealed a group of neurons that upon stimulation were inhibited in a frequency-dependent manner $\left(\mathrm{LI}_{50 \%}=14 \mathrm{~Hz}\right)$. It is seen that, for the inhibitory response in the Time out epoch, the neural activity recovered much faster than for the activated neurons.

\section{Population activity during the optogenetic stimulation}

Figure $7 C$ shows the population (381 aNAcSh neurons) activity of the evoked responses induced by optical stimulation. A population PCA analysis was used to better visualize the neuronal activation pattern of the evoked responses (see Materials and Methods). The figure shows the color-coded $Z$-score PSTHs of all 381 neurons that were modulated (or not) by optical stimulation and then sorted using the loading of each neuron in the first PCA. It is seen that the optical stimulation activated the $34 \%$ (129 of 381 ) of neurons, inhibited $12 \%$ (46 of 381 ), and left the majority unaffected. Overall, the aNAcSh population faithfully reflected all stimulation frequencies (Fig. 7C, black trace $Z$-score, $\mathrm{Sp} / \mathrm{s}$ ). During the Laser epoch, the aNAcSh population activity anticorrelated with the rapid suppression of the licking rate for sucrose (red traces).

For each neuron, we also compared, using a two-way ANOVA, the firing rates, during the Before $(-1$ to $<0 s)$ vs the Laser epoch (responses from 0 to $1 \mathrm{~s}$ ), as a function of stimulation frequency. We found that only $46 \%$ (175 of 381) of the neurons displayed a significant main effect for epoch (Before vs Laser epochs) and frequency, with a significant interaction between epoch and frequency (All $p$ values $<0.05$ ). From the neurons with a significant modulation, 34\% (129 of 381) were activated (red) and $12 \%$ (46 of 381) were inhibited (Fig. $7 D$, blue dots; scatter plot).

To measure the strength with which single-unit activity was phase-locked to the photostimulation, we used a multitaper coherence analysis between evoked spikes and laser frequencies (see Materials and Methods). With this analysis, we found that $67 \%$ (257 of 381) of aNAcSh neurons were significantly entrained for at least one of the tested frequencies. Overall, we observed that the higher the photostimulation frequency, the greater the number of aNAcSh neurons that were entrained (Fig. 7E; $n=142$ coherent neurons at $4 \mathrm{~Hz}, n=186$ for $7 \mathrm{~Hz}, n=210$ for $14 \mathrm{~Hz}, n=207$ for $20 \mathrm{~Hz}$ ). Because the coherence ranges between 0 and 1 (with 0 meaning no correlation between spikes and laser stimulation, and 1 a perfect correlation in both phase and frequency), we found that the coherence increased with increasing photostimulation frequency. The average coherence induced for each laser frequency is shown in Figure $7 E$ (right) [Kruskal Wallis $F_{(3,741)}=$ $18.78, p<0.0003$ ]. Neurons entrained by the $20 \mathrm{~Hz}$ photostimulation displayed a significantly higher coherence in comparison with the $14 \mathrm{~Hz}$ photostimulation ( $p<0.0001$; see Fig. $7 E$, right). These data demonstrate that a large proportion of aNAcSh neurons covary with optical stimulation, and their coherence strength increased with increasing laser frequency, rationalizing why higher frequencies more efficiently stop licking.

To demonstrate that the expression of ChR2 was responsible for the laser stimulation to suppress licking for sucrose, we used the same protocol on WT mice and found that stimulation of WT mice did not interrupt their licking for sucrose (data not shown). Likewise, in the WT mice, photostimulation did not significantly modulate the discharges of any of the 100 aNAcSh neurons and neither were these neurons significantly entrained to any laser frequency (Coherence analysis; data not shown).

\section{Responses during both the Laser and Time out epoch predict the delay to resume licking}

We next inquired whether the firing rate during the Laser and the Time out epochs could be used to predict, on a trial-by-trial basis, the delay to resume the intake of sucrose. This was accomplished by fitting a robust linear regression to model the delay in resuming licking (after optical stimulation) using as predictor variables, the firing rate in both epochs (see Materials and Methods). In the Laser epoch, the firing rate of $22.8 \%$ ( 87 of 381) of aNAcSh neurons could be used to predict the delay in resumption of licking. In the Time out epoch, only $8.6 \%$ (33 of 381) of the neurons displayed a significant coefficient (with a $p<0.05$ ). Finally, in both epochs, $7.6 \%(n=29)$ of the neurons had a significant contribution. The remaining $61 \%(n=232)$ of neurons were not significantly modulated in any epoch. The data suggest that the modulations in firing rate especially in the "Laser," but also in the Time out epoch could predict the delay of mice to resume licking.

\section{Feeding modulated neurons and modulations induced by photoactivation of glutamatergic aNAcSh fibers}

Previous studies have shown that, during the consumption of palatable solutions, aNAcSh neurons are mainly inhibited (Roitman et al., 2005; Krause et al., 2010; Tellez et al., 2012), suggesting that a pause in aNAcSh spiking activity, which likely arises from the inhibition of $\mathrm{MSND}^{+}$neurons (O'Connor et al., 2015), gates sucrose feeding, and that electrical stimulation of these fibers presumably activates this type of neuron to stop feeding (Krause et al., 2010). Based upon these results, we analyzed whether the activation of glutamatergic aNAcSh fibers would exhibit a preference for activating aNAcSh neurons that were inhibited while the animals were licking for sucrose. Figure $8 A$ (left) shows the population $Z$-score responses of aNAcSh neurons under conditions when the animals approached the sipper $(-1$ and $<0 \mathrm{~s})$ to begin a "Before" epoch $(t=0 \mathrm{~s}$; indicated by the vertical white line). In this regard, it is important to note that, for the subsequent four licks, the laser is OFF. The right hand panel shows the same neurons ordered as in the left panel only here the time between -0.5 and $0 \mathrm{~s}$ indicates the "Before" epoch, and the vertical white line indicates the time the laser was turned ON. Here the responses of the Laser epoch are normalized to the "Before" epoch, which is why they appear not to be modulated in this epoch. The nomenclature for the classification of these neurons is as follows: left panel (inhibited (Inh), activated (Act) and not modulated (NM) and right side panel refers to whether or not the evoked responses covary (CoV) with the $20 \mathrm{~Hz}$ laser stimulation. For example, the uppermost panel labeled Inh/CoV means that the neurons were inhibited upon the onset of licking and the evoked response covaried with the laser stimulation (at $20 \mathrm{~Hz}$ ).

For the left hand panel, it is seen that $20 \%$ (78 of 381) aNAcSh neurons were inhibited during licking (top two panels), 13\% (49 of 381) were activated (bottom two panels), and 67\% (254 of 381) were unmodulated. With regard to the right hand panel, $62 \%$ (236 of 381) of the neurons covaried with the laser stimulation (at either 14 and/or $20 \mathrm{~Hz}$ ). In this manner, the five neuronal populations were categorized as follows: Inh/CoV 59\% (46 of 78), Inh/noCoV 41\% (32 of 78), Act/CoV 61\% (30 of 49), Act/noCoV $39 \%$ (19 of 49), and NM/CoV 63\% (160 of 254). Together, these data show that photoactivation of glutamatergic aNAcSh fibers can modulate aNAcSh neurons independently of whether they were inhibited, activated, or not modulated by licking. 
A

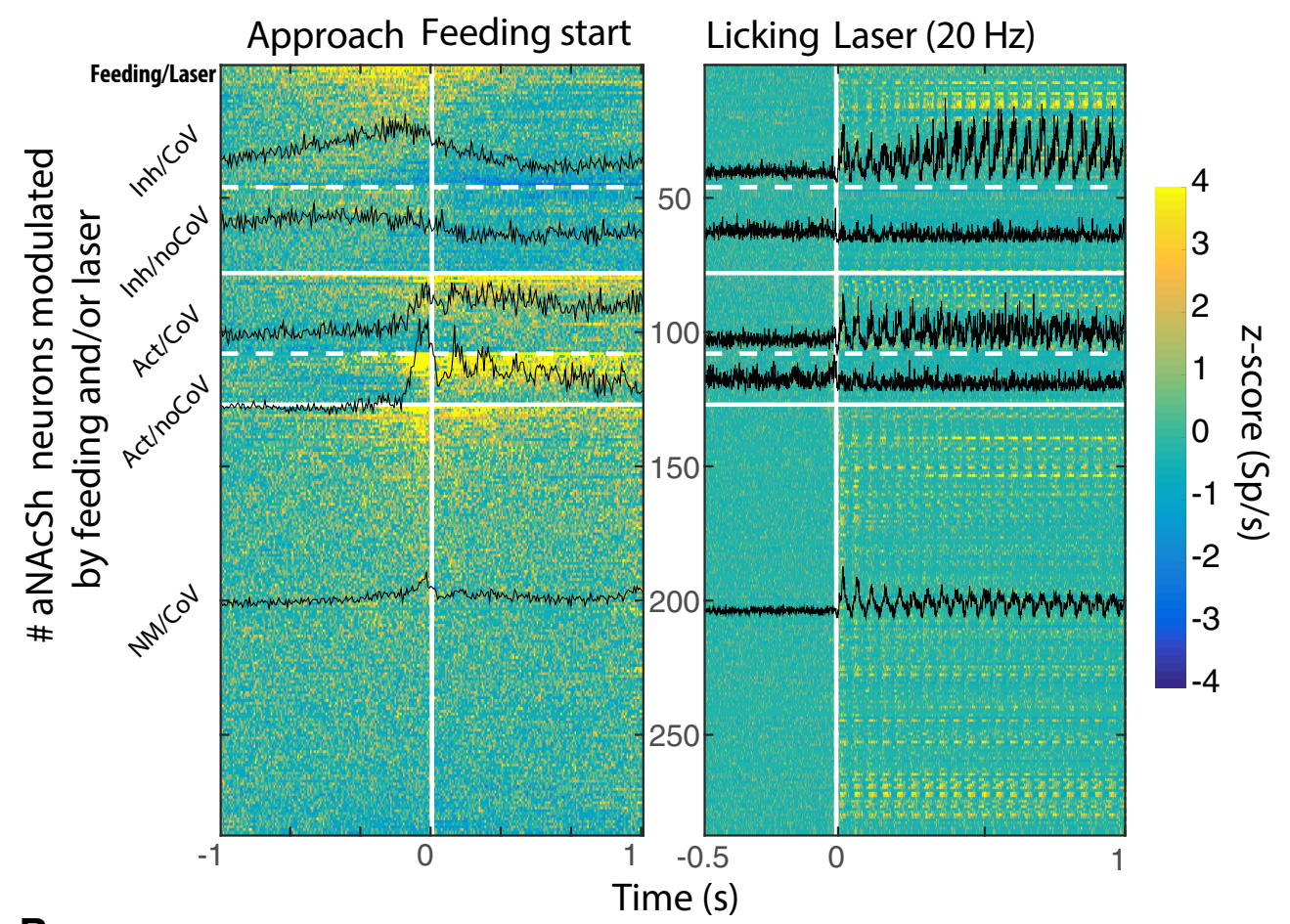

B

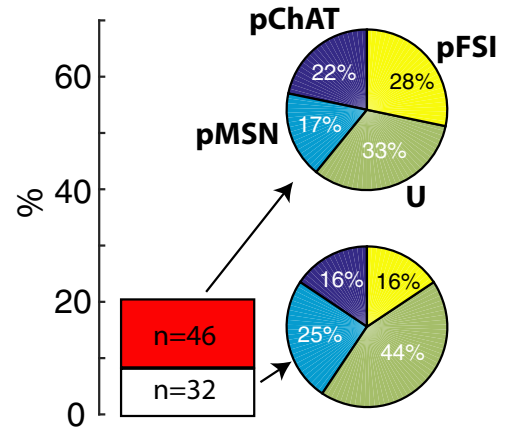

Inhibited
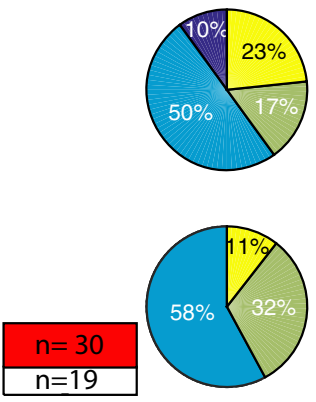

Activated
—Laser covary
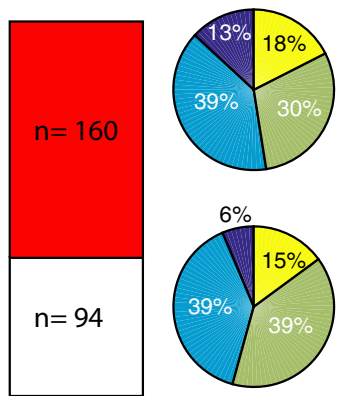

Not modulated

\section{Modulations induced by sucrose feeding}

Figure 8. Feeding modulated and optically stimulated aNACSh glutamatergic fibers. $\boldsymbol{A}$, Left, Normalized firing rate (relative to -1.5 to -1 activity) of aNAcSh neurons modulated by the initiation (time $=0 \mathrm{~s}$ ) of feeding (licking for sucrose). They were classified as inhibited (Inh), activated (Act), or not modulated (NM). Right, Responses of the same neurons, but their responses were now aligned (time $=0 \mathrm{~s}$ ) to the onset of laser stimulation (at $20 \mathrm{~Hz}$ ) as a function of whether they covaried $(\mathrm{CoV}$ ) or did not covary (noCoV) with the laser stimulation. $\boldsymbol{B}$, Plots of the percentage of putative pMSN, pFSI, and pChAT aNAcSh neurons that were modulated (Inhibited, Activated, and Not modulated) by feeding sucrose. Red rectangle represents the number of neurons that were coherent (covary) with laser stimulation. White rectangle represents the number of neurons that did not covary with the laser stimulation. Right of each bar, Putative cell type of neurons (see Materials and Methods, including neurons that could not be identified [U]) that were modulated in each of the six groups. Percentages may not total $100 \%$ because of rounding.

Because the aNAcSh contains many types of neurons, including MSNs, FSIs, and ChAT interneurons (Tepper et al., 2010), we tested whether optical stimulation in the aNAcSh would selectively activate one neuronal class. By using a variety of their firing pattern characteristics and waveform shapes, we could putatively classify the neuronal types (see Materials and Methods). Figure $8 B$ shows the putative cell-type of neurons modulated in each of the six groups (including neurons that could not be identified $[\mathrm{U}])$. The red block of the rectangle gives the number of neurons that were coherent (covary) with laser stimulation, and the white block in the rectangle gives the number of neurons that did not covary with the laser stimulation. It is seen that the stimulation of glutamatergic aNAcSh fibers activated all three putative types of aNAcSh neurons.

Photostimulation in the aNAcSh fibers modulates $M P F C$ neurons Because a primary cortical projection area to the aNAcSh arises from cortical layer $\mathrm{V}$ pyramidal neurons from the mPFC (Britt et al., 2012), we explored whether this cortical area could be activated either antidromically and/or polysynaptically by photostimulating aNAcSh glutamatergic fibers. Figure $9 A$ shows two representative $\mathrm{mPFC}$ responses to laser stimulation. In the top, the stimulation evokes a probable antidromic early monosynapatic single action potential (onset $=4.2 \pm 0.03 \mathrm{~ms}$ ) followed by 


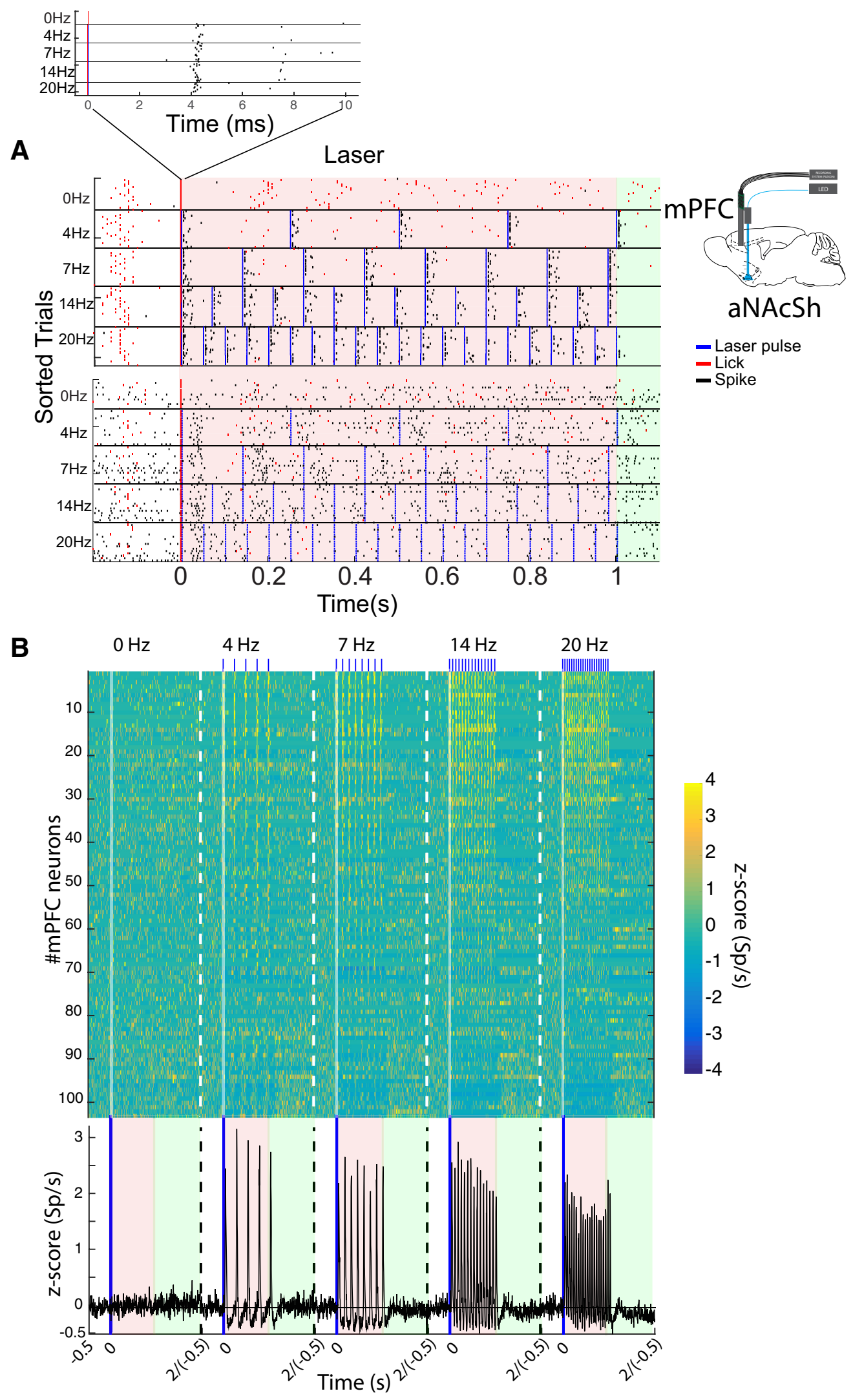

Figure 9. Photostimulation of aNACSh fibers activate mPFC neurons. A, Raster plots of two neurons recorded in two different sessions of licking task for sucrose having Baseline, Laser, and Time out epochs. Top, Neuronal response reliably fired an early single spike (onset $=4.2 \pm 0.03 \mathrm{~ms}$ ) after a pulse of optical stimulation (Top, Inset) and sporadically and with more jitter it evoked a second spike. Bottom, Raster plot represents a neuronal response that was inhibited by laser stimulation (more evident at higher frequencies). The conventions are the same as in Figure 7. Right, Inset, Schematic diagram of the stimulation and recording protocol. $\boldsymbol{B}$, Plots of the Z-score PSTH for 113 neurons recorded in the mPFC cortex during this task. Neurons ( $y$-axis) were sorted as a function of the first PCA scores. $x$-axis indicates the binned neuronal activity $(\sim-0.5$ to $2 \mathrm{~s})$. For all concatenated types of trials, the first photostimulation was at time $=0 \mathrm{~s}$. Bottom, Average $Z$-score PSTH (black trace) of all mPFC-recorded neurons (for visualization purposes, the lick responses are not shown). Pink and green shadows represent the Laser and Time out epochs, respectively. 
A

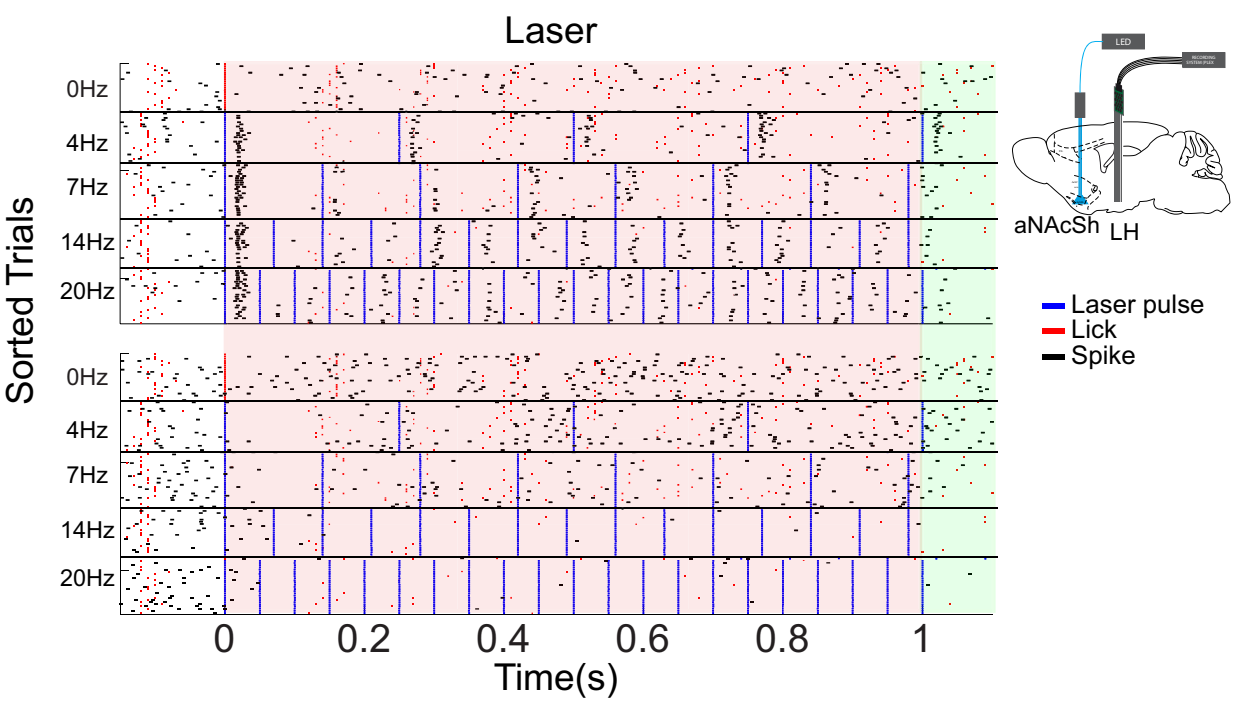

B

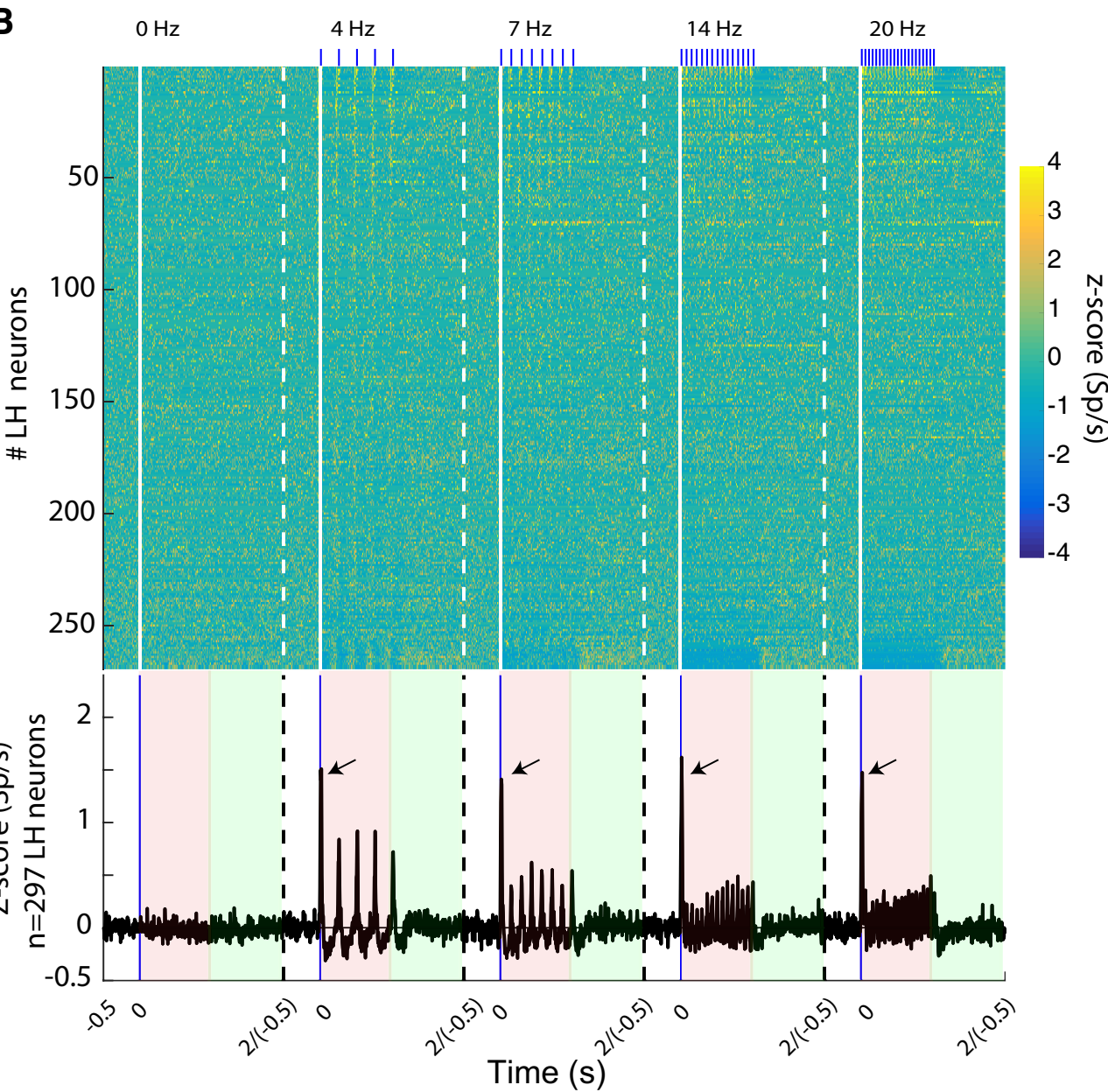

Figure 10. Photostimulation of aNACSh's fibers modulate the discharge rate of LH neurons. A, Raster plot of two neurons simultaneously recorded during the licking task for sucrose as described in Figure 7. Also shown is a schematic of the recording setup. Referring to the upper $L H$ response, it is seen as the first laser pulse generates a transient burst but in subsequent light pulses, especially at higher frequencies its responses were greatly attenuated. Bottom, The neuron is an example of a $\mathrm{LH}$ neuron that was inhibited by laser stimulation $\boldsymbol{B}$. The color code population Z-score PSTH for 297 LH neurons recorded while mice performed the licking task. Top, Neurons that were activated by the laser. Bottom, Neurons that were inhibited by laser stimulation. For the $z$-score analysis (bottom), pink and green shadows represent the Laser and Time out epochs, respectively. Arrows indicate the response to the first laser pulse. Black trace represents the normalized population PSTH of all neurons recorded. 

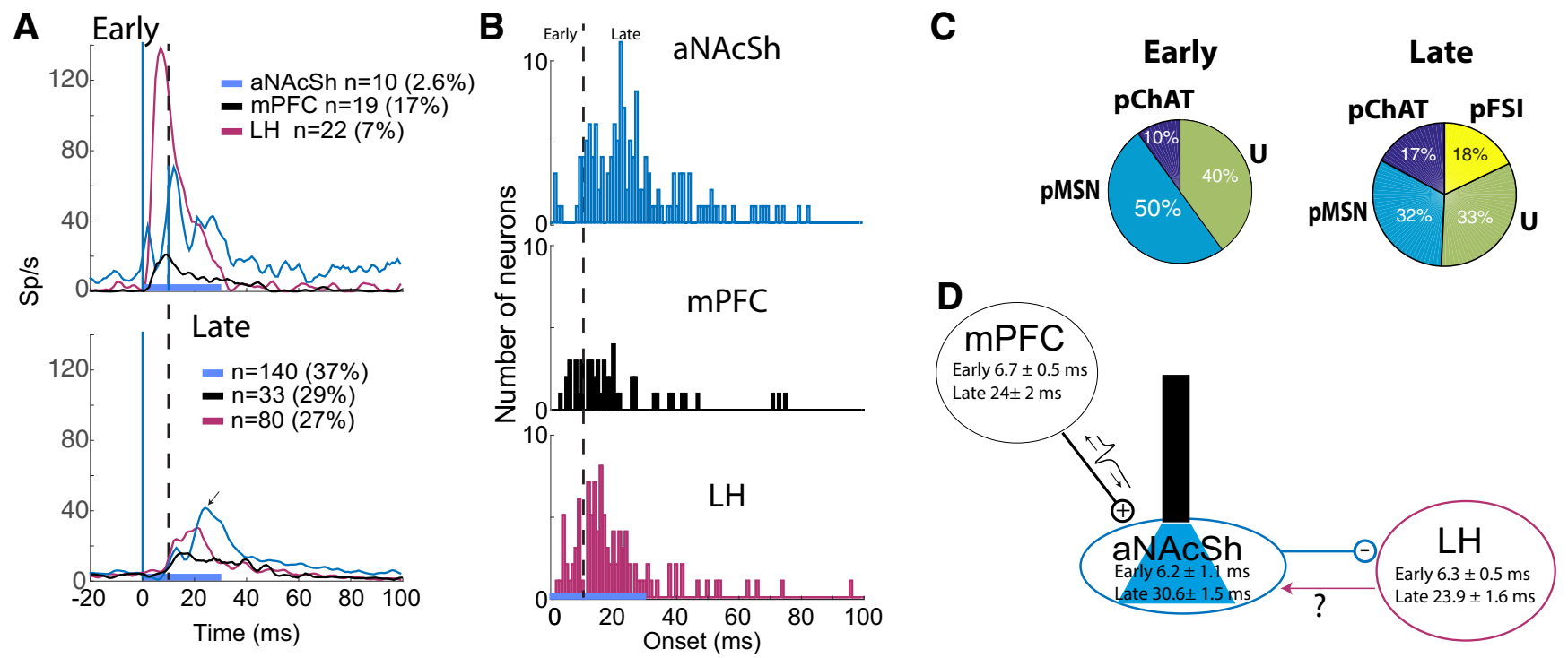

Figure 11. Photostimulation of aNACSh's fibers rapidly modulate cortical and subcortical network activity encompassing the mPFC, LH, and the aNAcSh. A, Top, Population PSTH responses in the three tested brain regions of early evoked responses (monosynaptic) during the first laser pulse ( $30 \mathrm{~ms}$ blue line on abscissa) in $4 \mathrm{~Hz}$ trials. Bottom, Same as above but plots the long latency responses (polysynaptic) as a function of brain region. Vertical dashed line indicates the division $(10 \mathrm{~ms})$ between early versus late responses. $\boldsymbol{B}$, Number of neurons with statistically significant onsets after the first light pulse. C, Pie chart showing the proportion of putative cell types recorded in the aNACSh for the early and late responses. D, Schematic representation of antidromic and orthodromic generation of action potential induced by photostimulation of glutamatergic aNAcSh fibers. The numbers in each brain region indicate the average latency onsets in the mPFC, aNAcSh, and LH neurons. In all cases, the population was subdivided in early and late responses, indicated by the vertical dashed line (at $10 \mathrm{~ms}, \boldsymbol{B})$.

a sporadic and more variable second spike. This type of neuronal response rapidly spiked after each optical pulse, although with less reliability with subsequent light pulses. An example of a late polysynaptic response followed by inhibition is shown at the bottom. It is seen that the evoked burst responses were inhibited by stimulation at 14 and $20 \mathrm{~Hz}$. Figure $9 \mathrm{~B}$ shows the populationevoked responses of $113 \mathrm{mPFC}$ neurons. Of these, $45 \%$ (51 of 113 ) were significantly modulated by the laser stimulation and of this population $21 \%$ ( 11 of 51 ) were inhibited and $79 \%$ ( 40 of 51 ) were activated [two-way ANOVA, all $p$ values $<0.05$ ]. The $Z$-score for the entire population is seen in the bottom panel (see black trace). Photostimulation also entrained a large portion of 113 neurons recorded $[4 \mathrm{~Hz} n=53(46 \%), 7 \mathrm{~Hz} n=64(56 \%), 14$ $\mathrm{Hz} n=73(64 \%), 20 \mathrm{~Hz} n=58(51 \%)]$ and the coherence significantly increased as a function of frequency [Coherence value; $4 \mathrm{~Hz}=0.22 \pm 0.01,7 \mathrm{~Hz} 0.27 \pm 0.01,14 \mathrm{~Hz} 0.32 \pm 0.01,20$ $\mathrm{Hz} 0.33 \pm 0.02$ Kruskal-Wallis, $p<0.05]$. Thus, photoactivation of excitatory aNAcSh fibers can both antidromically and polysynaptically (perhaps via a corticocortical and/or thalamocortical interaction) evoke neuronal activity in the mPFC.

Photostimulation of aNAcSh fibers modulates neuronal activity in the $L H$

Because there are reciprocal projections of the $\mathrm{LH}$ and aNAcSh (O'Connor et al., 2015), we also explored the effect of photostimulating aNAcSh fibers on LH neuronal activity. Figure $10 \mathrm{~A}$ shows two representative responses. In the top, it is seen that optical stimulation evokes a single action potential. This is most evident at $4 \mathrm{~Hz}$ as the reliability of the evoked spikes decreases with increasing frequency but still covaries with laser stimulation. In contrast, the evoked responses shown in the bottom are inhibited by optical stimulation. These same activation patterns are observed for the LH population. Specifically, 15\% (45 of 297) of LH neurons were significantly modulated by optical stimulation, and of those, 14 (31\%) were inhibited and 31 (69\%) were significantly activated (as uncovered by a two-way ANOVA). These activated responses were mainly due to increases in spike rate evoked by the first laser pulse (Figs. 10, 11). In contrast with the previous results in the aNAcSh and $\mathrm{MPFC}$, the coherence analysis uncovered that the higher laser frequencies did not significantly induced a stronger coherence [Coherence value; $4 \mathrm{~Hz}=0.29 \pm$ $0.02,7 \mathrm{~Hz} 0.28 \pm 0.01,14 \mathrm{~Hz} 0.27 \pm 0.015,20 \mathrm{~Hz} 0.30 \pm 0.018$ Kruskal-Wallis $p=0.78$, not significant], neither entrained more neurons as a function of laser frequencies $[4 \mathrm{~Hz} n=69$ neurons (23\%), $7 \mathrm{~Hz} 78$ (26\%), $14 \mathrm{~Hz} 82$ (27\%), and $20 \mathrm{~Hz} 60$ (20\%)]. In summary, optical stimulation of aNAcSh fibers modulate LH neurons such that it initially activates them, but on subsequent stimulations the magnitude of response decreases.

\section{Latencies in the aNAcSh, LH, and mPFC evoked by optogenetic} stimulation of aNAcSh fibers

To obtain a better understanding of how the signals evoked by stimulation of glutamatergic fibers are transmitted throughout the aNAcSh, $\mathrm{LH}$, and mPFC network, we measured for the $4 \mathrm{~Hz}$ trials the first statistically significant change in the firing rate (latency) after the first $30 \mathrm{~ms}$ laser pulse. We recorded a spectrum of latencies ranging from 2 ms to hundreds of milliseconds. Based on previous studies for monosynaptic transmission, that ranged from 1 to $10 \mathrm{~ms}$ (Buonomano, 2003), we divided those responses that were $\leq 10 \mathrm{~ms}$ (as early) and those $>10 \mathrm{~ms}$ as late (assumed to be polysynaptic; Fig. $11 A$, top and bottom panels, respectively, dashed line). Figure $11 A$ shows the temporal dynamics of the population PSTHs of early (top) and late (bottom) responsive neurons. The distribution of latency onsets in the three areas is seen in Figure $11 B$. The onsets of the early responses were not significantly different among brain regions: $\mathrm{mPFC}(6.7 \pm 0.5$ $\mathrm{ms}), \mathrm{LH}(6.3 \pm 0.5 \mathrm{~ms})$, and the $\mathrm{aNAcSh}(6.2 \pm 1.1 \mathrm{~ms})$ (Kruskal-Wallis, not significant). However, the early LH responses were of larger magnitude compared with those in aNAcSh and mPFC. We are aware of the possibility that these early responses in $\mathrm{LH}$ (7\% of neurons) might reflect either anti- 
dromic activations or a direct activation of glutamatergic fibers that target the LH (Fig. 11D) (Mogenson et al., 1983).

One reason that the aNAcSh showed a smaller proportion of monosynaptic activations (only 10 of 381 neurons; $2.6 \%$ ) than the other two areas is, because of the tonic lateral inhibition by MSNs (Tepper and Bolam, 2004). Importantly, the early responses were primarily composed of pMSNs (50\%) and only a few putative interneurons (Fig. 11C). In contrast to the mPFC, the aNAcSh had the larger proportion of late responses recruited (37\%). Late responses had relatively similar proportions of both pMSN and putative interneurons, indicating that late responses reflect interactions between more local striatal ensembles.

Analysis of the late responses showed some different temporal dynamics than the early ones (Fig. 11A, bottom). That is, the late onsets were significantly different among brain regions (KruskalWallis $\left.F_{(2,252)}=13.3, p=0.0013\right)$ : the onsets were $\mathrm{mPFC}(24 \pm$ $2 \mathrm{~ms}), \mathrm{LH}(23.9 \pm 1.6 \mathrm{~ms})$, and aNAcSh $(30.6 \pm 1.5 \mathrm{~ms})$. A post hoc analysis revealed that only late responses in the aNAcSh were significantly delayed relative to those in LH $(p<0.05)$. Moreover, there was a nonsignificant trend between the aNAcSh and mPFC ( $p>0.05$, not significant). These data indicate that when late (polysynaptic) responses in the aNAcSh were maximal (see arrow), LH responses were mostly inhibited (Fig. 11B, bottom).

In summary, these data indicate that optogenetic stimulation of excitatory afferents in the aNAcSh rapidly influences a widebrain network (Kumar et al., 2013), minimally encompassing the mPFC (excite) aNAcSh (inhibit) the LH feeding hedonic circuit.

\section{Discussion}

The aNAcSh is a component of a neural network involved in both feeding and reward. Although these processes can be related, reward is a mental state and feeding is a goal-directed behavior having a motor component indicating that different networks are necessarily involved. Although an intact mesoaccumbal dopamine system has been shown to be necessary for normal feeding (Szczypka et al., 1999), and for the attribution of incentive value to rewarding stimuli (Rossi and Yin, 2015), recent evidence suggests that the interaction between dopamine and glutamate in the aNAcSh is an important factor in mediating reward and feeding (Britt et al., 2012). Here we investigated this interaction in detail by optically stimulating aNAcSh fibers in mice that express $\mathrm{ChR} 2$ primarily in cortical glutamatergic neurons that project to the aNAcSh (Fig. 1). We found that Thy1-ChR2 mice make a good model to mimic bulky fiber stimulation induced by electrical stimulation of the NAc (Krause et al., 2010; Vizcarra-Chacón et al., 2013). Here we report that unilateral stimulation of aNAcSh excitatory afferents both activated and inhibited MSNs and interneurons in the aNAcSh, in a manner that maintains firing rate homeostasis. Importantly, optical stimulation of these inputs produces a transient cessation of feeding that is independent of the caloric and hedonic value of sucrose, and the animal's state of satiation. That this stimulation was rewarding (wanting and learning components) was demonstrated when the transgenic mice learned to self-stimulate by licking an empty sipper (Fig. 4) and to nose-poke (Fig. 5). To obtain the network responses related to the behavioral task of licking for sucrose, single-unit responses were obtained in three components of the feedingreward network: the aNAcSh, LH, and mPFC. In all areas, stimulation of aNAcSh fibers both activated and inhibited neurons, some of which covaried with optical stimulation. One population of licking-inhibited pMSNs was also activated by optical stimulation (Fig. 8), suggesting their relevance in the cessation of feeding (O'Connor et al., 2015). This population, or another covarying one (Fig. 8), could represent a reward signal. Latency analysis uncovered important propagation properties (monosynaptic-polysynaptic) of this network. In summary, we showed the importance of activating glutamatergic aNAcSh fibers in reward and feeding.

\section{Behavioral studies}

Behavioral studies in food- and water-deprived mice revealed that unilateral optical activation of aNAcSh glutamatergic afferents exerts an immediate and transient stoppage of sucrose feeding (Figs. 2-4). This behavior persisted even though rodents find it hard to stop, especially when licking sucrose solutions (Weiss and Di Lorenzo, 2012; Perez et al., 2013).

The wanting aspect of reward in the aNAcSh was evident in sucrose naive Thy1-ChR2 mice that learned to lick an empty sipper or to nose-poke the Active port to self-photoactivate aNAcSh afferents (Figs. 4, 5). It follows that stimulation of glutamatergic fibers can trigger an incentive "wanting" signal of reward that can reinforce operant behaviors, such as empty licking and nose-poking, and thus promote self-stimulation learning (Robinson and Berridge, 2008).

One result obtained using a block open-loop stimulation protocol that prevented hungry transgenic mice from initiating the intake of sucrose (Fig. 6B) is that, during the unstimulated blocks, they consumed sucrose at a faster rate than their WT littermates. We posit that they use this behavioral strategy to compensate for the "lost time in getting the available reward." We did not identify a neural correlate of this behavior in the aNAcSh and thus assume it is in other brain areas.

\section{Dopaminergic and glutamatergic pathways in and out of the aNAcSh}

Britt et al. (2012) showed that optogenetic stimulation of glutamatergic inputs, including those from the mPFC, ventral hippocampus, and BLA, modulate reward. That is, in all cases, these mice learned to nose-poke to self-stimulate each of these individual afferents, indicating the importance of the release of glutamate in the NAc itself to induce reward (at least in the sense of wanting). Our results agree with this contention because bulky activation of glutamatergic fibers in the aNAcSh was also rewarding (Figs. 4, 5). Moreover, because activation of mPFC, excitatory afferents evoke the release of both dopamine and glutamate in the aNAcSh (Quiroz et al., 2016), it follows that both dopamine and glutamate have roles in reward (Britt et al., 2012; Stuber et al., 2012). Here, we showed that aNAcSh excitatory fibers are also involved in feeding.

\section{Population responses in the aNAcSh, mPFC, and LH evoked by the activation of glutamatergic fibers}

Recordings from aNAcSh slices demonstrated that optical stimulation of excitatory aNAcSh afferents can activate MSNs and FSIs (Fig. 1). However, stimulation of glutamatergic aNAcSh neurons results in neurons being activated or inhibited, but at the population level they maintain spiking homeostasis (Figs. $6 E, 7 C, D$ ). Of interest are our classifications of aNAcSh cell types that show both feeding and optical stimulation modulate pMSN, pFSI, and pChAT neurons (Fig. 8). In this regard, O'Connor et al. (2015) found that aNAcSh GABAergic $\mathrm{MSND1}^{+}$neurons project to GABAergic neurons in the LH to stop feeding. Here we found that approximately half of the neurons that were inhibited by licking were activated by the laser stimulation (Fig. 8, Inh/CoV), rationalizing why activation of excitatory aNAcSh afferents rapidly stop sucrose feeding (O'Connor et al., 2015). Although the Inh/Cov neurons are involved in feeding, the 
neurons involved in reward could be any of those that covary with laser stimulation (i.e., Inh/Cov, Act/Cov, and NM/Cov; Fig. 8). This issue can be addressed by labeling specific subpopulations of aNAcSh afferents.

Horst and Laubach (2013) found that mPFC neurons respond to the initiation and termination of sucrose consumption, suggesting a role for them in monitoring feeding behavior. Our data suggest that glutamatergic afferents from the mPFC and from other regions, including the amygdala and ventral hippocampus (Britt et al., 2012) act as an upstream controller of the aNAcSh-LH circuit that gates feeding. Because the mPFC was both antidromically and polysynaptically activated by optogenetic stimulation of excitatory aNAcSh afferents (Fig. 9A), it follows that release of glutamate activates local aNAcSh circuitry (Fig. 7). Because GABAergic MSND1 ${ }^{+}$aNAcSh neurons inhibit GABAergic LH neurons (O'Connor et al., 2015), it can explain why electrical stimulation of aNAcSh fibers inhibits activity in many LH neurons (Mogenson et al., 1983). Our single-unit recordings in LH also revealed a robust inhibition of population responses recorded in the $\mathrm{LH}$, especially after the second laser pulse (Figs. 10,11). This is relevant because activation of GABAergic neurons in the LH induces consummatory behavior, whereas silencing them reduces consumption (Jennings et al., 2015). Importantly, LH GABAergic neurons modulate consumption of any taste stimuli, regardless of caloric content or biological relevance (Navarro et al., 2016). Thus, the above data and our results (Fig. 4) suggest that the hedonic circuit seems to operate independently of caloric content.

Brain network (monosynaptic and polysynaptic) propagation Optical stimulation of the aNAcSh fibers evoked responses in the aNAcSh, mPFC, and LH (Figs. 7, 9, 10). These results are consistent with studies of electrical DBS of NAc that recruits a large brain network, including orbitofrontal and infralimbic cortex, and the NAc shell itself (McCracken and Grace, 2009; Vassoler et al., 2013). To better understand how excitatory aNAcSh afferents transmit their modulatory influence into the studied brain network, we divided early (monosynaptic) and late (polysynaptic) latencies. First, we found that the three recorded brain regions were rapidly engaged by activation of aNAcSh fibers because early onsets were not significantly different among them. However, because transgenic mice expressed ChR2 in cortical projection neurons, it was expected that more mPFC neurons with monosynaptic responses would be antidromically recruited as was the case (Taber and Fibiger, 1995). Second, activation of mPFC neurons (and probably other glutamatergic inputs, including those in the BLA, ventral hippocampus, and thalamus) that project to the aNAcSh release glutamate (Quiroz et al., 2016) and activate some early aNAcSh responses (Fig. 11A), including pMSNs and interneurons (Fig. 11C). Thus, the few monosynaptic responses could be explained by lateral inhibition exerted by MSNs that could mask early responses (Tepper and Bolam, 2004). In contrast, the aNAcSh had more late modulations than MPFC, with longer onsets relative to LH. Late responses in the aNAcSh may arise from interactions between local striatal ensembles because they contain similar proportions either pMSNs or putative interneurons (Fig. 11C) and/or from inter-region polysynaptic interactions, from cortical neurons firing at different times into the same MSN (Vizcarra-Chacón et al., 2013). Furthermore, we found that the late peak recorded in the aNAcSh was out of phase and anticorrelated with the late peak recorded in the LH. These data suggest that aNAcSh neurons release sufficient quantities of
GABA as to inhibit LH late evoked-responses (Fig. 11A, arrow), and this inhibitory tone increases with subsequent laser pulses.

In conclusion, here we found that optical stimulation of glutamatergic aNAcSh fibers is rewarding and it exerts a rapid control over an ongoing consummatory action, such as feeding, regardless of sucrose's caloric content and an animal's state of satiation. These results indicate that the same optogenetic stimulation of excitatory glutamatergic afferents in the aNAcSh can modulate both feeding and reward networks.

\section{References}

Adams JC (1981) Heavy metal intensification of DAB-based HRP reaction product. J Histochem Cytochem 29:775. CrossRef Medline

Arenkiel BR, Peca J, Davison IG, Feliciano C, Deisseroth K, Augustine GJ, Ehlers MD, Feng G (2007) In vivo light-induced activation of neural circuitry in transgenic mice expressing channelrhodopsin-2. Neuron 54: 205-218. CrossRef Medline

Berridge CW, Stratford TL, Foote SL, Kelley AE (1997) Distribution of dopamine beta-hydroxylase-like immunoreactive fibers within the shell subregion of the nucleus accumbens. Synapse 27:230-241. CrossRef Medline

Berridge KC, Kringelbach ML (2015) Pleasure systems in the brain. Neuron 86:646-664. CrossRef Medline

Britt JP, Benaliouad F, McDevitt RA, Stuber GD, Wise RA, Bonci A (2012) Synaptic and behavioral profile of multiple glutamatergic inputs to the nucleus accumbens. Neuron 76:790-803. CrossRef Medline

Buonomano DV (2003) Timing of neural responses in cortical organotypic slices. Proc Natl Acad Sci U S A 100:4897-4902. CrossRef Medline

Gutierrez R, Carmena JM, Nicolelis MA, Simon SA (2006) Orbitofrontal ensemble activity monitors licking and distinguishes among natural rewards. J Neurophysiol 95:119-133. CrossRef Medline

Gutierrez R, Simon SA, Nicolelis MA (2010) Licking-induced synchrony in the taste-reward circuit improves cue discrimination during learning. J Neurosci 30:287-303. CrossRef Medline

Holt GR, Softky WR, Koch C, Douglas RJ (1996) Comparison of discharge variability in vitro and in vivo in cat visual cortex neurons. J Neurophysiol 75:1806-1814. Medline

Horst NK, Laubach M (2013) Reward-related activity in the medial prefrontal cortex is driven by consumption. Front Neurosci 7:56. CrossRef Medline

Jarvis MR, Mitra PP (2001) Sampling properties of the spectrum and coherency of sequences of action potentials. Neural Comput 13:717-749. CrossRef Medline

Jennings JH, Ung RL, Resendez SL, Stamatakis AM, Taylor JG, Huang J, Veleta K, Kantak PA, Aita M, Shilling-Scrivo K, Ramakrishnan C, Deisseroth K, Otte S, Stuber GD (2015) Visualizing hypothalamic network dynamics for appetitive and consummatory behaviors. Cell 160:516-527. CrossRef Medline

Kelley AE, Berridge KC (2002) The neuroscience of natural rewards: relevance to addictive drugs. J Neurosci 22:3306-3311. Medline

Krause M, German PW, Taha SA, Fields HL (2010) A pause in nucleus accumbens neuron firing is required to initiate and maintain feeding. J Neurosci 30:4746-4756. CrossRef Medline

Kumar S, Black SJ, Hultman R, Szabo ST, DeMaio KD, Du J, Katz BM, Feng G, Covington HE 3rd, Dzirasa K (2013) Cortical control of affective networks. J Neurosci 33:1116-1129. CrossRef Medline

Lobo MK, Covington HE 3rd, Chaudhury D, Friedman AK, Sun H, DamezWerno D, Dietz DM, Zaman S, Koo JW, Kennedy PJ, Mouzon E, Mogri M, Neve RL, Deisseroth K, Han MH, Nestler EJ (2010) Cell type-specific loss of BDNF signaling mimics optogenetic control of cocaine reward. Science 330:385-390. CrossRef Medline

McCracken CB, Grace AA (2009) Nucleus accumbens deep brain stimulation produces region-specific alterations in local field potential oscillations and evoked responses in vivo. J Neurosci 29:5354-5363. CrossRef Medline

Mogenson GJ, Swanson LW, Wu M (1983) Neural projections from nucleus accumbens to globus pallidus, substantia innominata, and lateral preoptic-lateral hypothalamic area: an anatomical and electrophysiological investigation in the rat. J Neurosci 3:189-202. Medline

Navarro M, Olney JJ, Burnham NW, Mazzone CM, Lowery-Gionta EG, Pleil KE, Kash TL, Thiele TE (2016) Lateral hypothalamus GABAergic neu- 
rons modulate consummatory behaviors regardless of the caloric content or biological relevance of the consumed stimuli. Neuropsychopharmacology 41:1505-1512. CrossRef Medline

O'Connor EC, Kremer Y, Lefort S, Harada M, Pascoli V, Rohner C, Lüscher C (2015) Accumbal D1R neurons projecting to lateral hypothalamus authorize feeding. Neuron 88:553-564. CrossRef Medline

Perez IO, Villavicencio M, Simon SA, Gutierrez R (2013) Speed and accuracy of taste identification and palatability: impact of learning, reward expectancy, and consummatory licking. Am J Physiol Regul Integr Comp Physiol 305:R252-R270. CrossRef Medline

Porrero C, Rubio-Garrido P, Avendaño C, Clascá F (2010) Mapping of fluorescent protein-expressing neurons and axon pathways in adult and developing Thy1-eYFP-H transgenic mice. Brain Res 1345:59-72. CrossRef Medline

Quiroz C, Orrú M, Rea W, Ciudad-Roberts A, Yepes G, Britt JP, Ferré S (2016) Local control of extracellular dopamine levels in the medial nucleus accumbens by a glutamatergic projection from the infralimbic cortex. J Neurosci 36:851-859. CrossRef Medline

Robinson TE, Berridge KC (2008) The incentive sensitization theory of addiction: some current issues. Philos Trans R Soc Lond B Biol Sci 363: 3137-3146. CrossRef Medline

Roitman MF, Wheeler RA, Carelli RM (2005) Nucleus accumbens neurons are innately tuned for rewarding and aversive taste stimuli, encode their predictors, and are linked to motor output. Neuron 45:587-597. CrossRef Medline

Rossi MA, Yin HH (2015) Elevated dopamine alters consummatory pattern generation and increases behavioral variability during learning. Front Integr Neurosci 9:37. CrossRef Medline

Sciamanna G, Ponterio G, Mandolesi G, Bonsi P, Pisani A (2015) Optogenetic stimulation reveals distinct modulatory properties of thalamostriatal vs corticostriatal glutamatergic inputs to fast-spiking interneurons. Sci Rep 5:16742. CrossRef Medline

Stratford TR, Kelley AE (1997) GABA in the nucleus accumbens shell participates in the central regulation of feeding behavior. J Neurosci 17: 4434-4440. Medline

Stuber GD, Sparta DR, Stamatakis AM, van Leeuwen WA, Hardjoprajitno JE,
Cho S, Tye KM, Kempadoo KA, Zhang F, Deisseroth K, Bonci A (2011) Excitatory transmission from the amygdala to nucleus accumbens facilitates reward seeking. Nature 475:377-380. CrossRef Medline

Stuber GD, Britt JP, Bonci A (2012) Optogenetic modulation of neural circuits that underlie reward seeking. Biol Psychiatry 71:1061-1067. CrossRef Medline

Szczypka MS, Rainey MA, Kim DS, Alaynick WA, Marck BT, Matsumoto AM, Palmiter RD (1999) Feeding behavior in dopamine-deficient mice. Proc Natl Acad Sci U S A 96:12138-12143. CrossRef Medline

Taber MT, Fibiger HC (1995) Electrical stimulation of the prefrontal cortex increases dopamine release in the nucleus accumbens of the rat: modulation by metabotropic glutamate receptors. J Neurosci 15:3896-3904. Medline

Tellez LA, Perez IO, Simon SA, Gutierrez R (2012) Transitions between sleep and feeding states in rat ventral striatum neurons. J Neurophysiol 108:1739-1751. CrossRef Medline

Tepper JM, Bolam JP (2004) Functional diversity and specificity of neostriatal interneurons. Curr Opin Neurobiol 14:685-692. CrossRef Medline

Tepper JM, Tecuapetla F, Koós T, Ibáñez-Sandoval O (2010) Heterogeneity and diversity of striatal GABAergic interneurons. Front Neuroanat 4:150. CrossRef Medline

Vassoler FM, White SL, Hopkins TJ, Guercio LA, Espallergues J, Berton O, Schmidt HD, Pierce RC (2013) Deep brain stimulation of the nucleus accumbens shell attenuates cocaine reinstatement through local and antidromic activation. J Neurosci 33:14446-14454. CrossRef Medline

Vizcarra-Chacón BJ, Arias-García MA, Pérez-Ramírez MB, Flores-Barrera E, Tapia D, Drucker-Colin R, Bargas J, Galarraga E (2013) Contribution of different classes of glutamate receptors in the corticostriatal polysynaptic responses from striatal direct and indirect projection neurons. BMC Neurosci 14:60. CrossRef Medline

Weiss MS, Di Lorenzo PM (2012) Not so fast: taste stimulus coding time in the rat revisited. Front Integr Neurosci 6:27. CrossRef Medline

Yarom O, Cohen D (2011) Putative cholinergic interneurons in the ventral and dorsal regions of the striatum have distinct roles in a two choice alternative association task. Front Syst Neurosci 5:36. CrossRef Medline 